\title{
Public Good Differentiation AND THE INTENSITY OF TAX COMPETITION
}

\author{
by
}

Ben Zissimos and Myrna Wooders

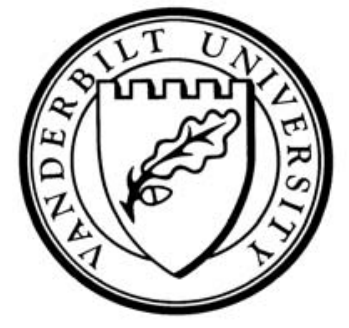

Working Paper No. 07-W10

June 2007

\section{DEPARTMENT OF ECONOMICS \\ VANDERBILT UNIVERSITY \\ NASHVILLE, TN 37235}

www.vanderbilt.edu/econ 


\title{
Public Good Differentiation and the Intensity of Tax Competition ${ }^{1}$
}

\author{
Ben Zissimos ${ }^{2}$
}

Myrna Wooders ${ }^{3}$

Vanderbilt University

First draft: November 2003

This version: June 2007

AbStract: We show that, in a setting where tax competition promotes efficiency, variation in the extent to which firms can use public goods to reduce costs brings about a reduction in the intensity of tax competition. This in turn brings about a loss of efficiency. In this environment, a 'minimum tax' counters the reduction in the intensity of tax competition, thereby enhancing efficiency. 'Split-the-difference' tax harmonization also potentially enhances efficiency but would not be agreed upon by governments because it lowers the payoff to at least one of them. This paper also presents an explanation for how traditionally high-tax countries have continued to set taxes at a relatively high rate even as markets have become more integrated.

KEYWORDS: asymmetric equilibrium, core-periphery, tax competition, tax harmonization.

JeL Classification Numbers: C72, H21, H42, H73, R50.

\footnotetext{
${ }^{1}$ An earlier version of this paper was circulated under the title 'Relaxing Tax Competition through Public Good Differentiation.' We would first like to thank an anonymous referee for pointing out a shortcoming with the notion of 'relaxing' tax competition, which prompted us to recast the paper in its present form. We would also like to thank Rick Bond, John Conley, Andrew Daughety, Tom Gresik, Jennifer Reinganum, David Wildasin and a referee for helpful comments and conversations about this paper. Finally, we thank seminar participants at Vanderbilt University, University of Oregon, University of Kentucky, FGV Rio de Janeiro, the Southern Economics Society Meetings in San Antonio, the PET '04 Conference in Beijing and the 2005 World Congress of the Econometric Society in London for their comments.

${ }^{2}$ Corresponding author: Dept. of Economics, Vanderbilt University, Nashville, TN 37235.

Tel: ++16153223339 .

E-mail: ben.zissimos@vanderbilt.edu

${ }^{3}$ E-mail: myrna.wooders@vanderbilt.edu.
} 


\section{Introduction}

This paper demonstrates how variation across firms in their requirements for public goods may bring about differentiation in the levels of public good provision across countries and, as a result, lead to a reduction in the intensity of tax competition. In the case of zero variation in firms' requirements for public goods, a benchmark case, tax competition between countries for mobile firms is intense and leads to an equilibrium outcome that is efficient (as in Brennan and Buchanan 1980). As the variation in firms' requirements for public goods is increased, the intensity of tax competition is reduced relative to the benchmark case; the level of public good provision becomes inefficiently low and the difference between the level of taxes across countries increases. ${ }^{4}$ The paper then raises the question of whether tax coordination can alleviate the inefficiency. A 'minimum tax' counters the reduction in the intensity of tax competition resulting from the variation in firms' public good requirements, and thus reduces inefficiency. Tax harmonization would potentially counter the reduction in the intensity of tax competition but would always be vetoed by the low-tax government. ${ }^{5}$

To obtain our results, we analyze a two-stage game of fiscal competition between national governments. In the first stage, each government sets a level of public good provision. The public good is only useful in the reduction of firms' production costs (there are no consumers in the model). In the second stage, each government sets its level of (lump-sum) taxes. The location of each firm is determined (nonstrategically) by where it will make the highest profits, given public good provision and taxes. An increase in a country's public-input level or a decrease in its tax attracts firms from the other country. Governments care about rents

\footnotetext{
${ }^{4}$ The notion of 'intensity of tax competition' as we use it here is parallel to the notion of 'intensity of price competition' as used in the industrial organization literature (Tirole 1998, Chapter 7). Variations of the term 'intensity of tax competition' are used informally elsewhere in the literature but as far as we know they have not been formalized.

${ }^{5}$ The literature on capital tax competition has focused on three different situations. The first concentrates on the presence of a 'fiscal externality,' whereby lowering the tax rate attracts capital to the jurisdiction. As a result, each government has an incentive to engage in wasteful competition for capital. The second, following Tiebout (1956), focuses on situations where competition among independent governments is like competition among firms and has desirable efficiency properties. The third setting combines features of the other two. On the one hand, competition introduces efficiency-enhancing incentives. On the other hand, such incentives operate in an environment characterized by market- or policy-failures that make a fully efficient equilibrium unattainable. The present paper is placed in the third setting. See Wilson (1999) and Wilson and Wildasin (2004) for comprehensive surveys of the tax competition literature. We will leave aside issues of commodity taxation, which are synthesized by Lockwood (2001).
} 
(tax revenue minus public-input costs). ${ }^{6}$ The efficient solution is asymmetric. The equilibrium exhibits the properties discussed above and is asymmetric. Note that, because the model exhibits a unique asymmetric equilibrium, the framework yields a novel explanation for how traditionally high-tax countries have continued to set taxes at a relatively high rate even as markets have become more integrated.

The relationship between public good provision and fiscal competition has already received some attention in the literature. Some prominent examples are the following. Brueckner (2000) considers Tiebout/tax competition in an environment where firms' public good requirements vary, and shows that firms whose requirements are similar sort themselves efficiently across jurisdictions. Hoyt and Jensen (2001) consider the capitalization of public education quality (i.e. a public good differentiated by quality) into house prices in the presence of tax competition. Justman, Thisse and van Ypersele (2002) consider fiscal competition when public good quality varies, and identify a 'fiscal agglomeration' property which defines an upper bound on the number of jurisdictions over which firms will locate. Each of these papers makes an important contribution. None of them, however, treats the limits created by differing public good requirements to efficiency gains that can be achieved through tax competition as we do in this paper. Also, none of these previous papers consider the merits of tax coordination. We will continue the discussion of how the present paper relates to the literature in Section 6 below.

The paper proceeds as follows. In Section 2 the basic model is set up. In Section 3 the efficient solution is solved for under the assumption that levels of public good provision and firm locations are chosen by a planner. Section 4 models a game of tax competition between countries, characterizing a non-cooperative equilibrium. In Section 5, policies of tax coordination are considered. Section 6 places the paper's contribution to the literature and draws conclusions.

\footnotetext{
${ }^{6}$ We assume that governments maximize rents but otherwise do not specify their motivation. For examples of other work on tax competition in which governments are rent maximizers, see Kanbur and Keen (1993), Hoyt (1995, 1999), Brueckner (2000), Keen and Katsogiannis (2003), and Devereux, Lockwood and Redoano (2006).
} 


\section{The Model}

There are two countries, $A$ and $B$, each of which has a government that sets the level of public good provision, $x_{A}$ and $x_{B}$ respectively, and the tax level, $\tau_{A}$ and $\tau_{B}$ respectively for its country. There is a set of firms, each of which is able to sell a single unit of a good. The costs of a firm depend on the level of taxation and the level of public good provision in the country where it locates. ${ }^{7}$ We will first specify the behavior of firms, after which we will turn to governments. Finally, we will set out the sequence of events in the policy-setting game.

Firms are not strategic. Each firm simply takes taxes and levels of public good provision as given and locates in the country where it makes the highest profits. ${ }^{8}$ The technologies of the firms are parameterized by points distributed uniformly on the unit interval. The value $s \in[0,1]$ uniquely identifies a firm and its technology. The technology of a firm $s$ reflects the extent to which public good provision reduces its costs. The cost-reducing impact of the public good on an individual firm operating in country $i \in\{A, b\}$ with technology $s$ is given by $s k x_{i}{ }^{\theta}$, where $x_{i}$ is the amount of public good provided in country $i$ and where $k \geq 0$ and $0<\theta<1$ are parameters. ${ }^{9}$ The parameter $\theta$ ensures that the effect of the public good is declining at the margin as we should generally expect. The parameter $k$ determines the overall impact of public good provision on profitability. ${ }^{10}$ Note that, under the present

\footnotetext{
${ }^{7}$ Since countries are ex ante symmetrical, firm location decisions and hence the boundaries of the countries are determined solely by the interaction of policy choices with firms' public good requirements. This is of course highly stylized, but serves to focus attention on the relationship between public good differentiation and tax competition. Additional features could be introduced to the model to make one country more attractive to firms than others, either by assuming that it is cheaper to locate/set up in one country than another or that there is an 'attachment to home,' but these would obscure the effects we want to focus on. See Hindriks (1999) for an example of where attachment to home is modeled in the context of tax (vs. transfer) competition.

${ }^{8}$ Our model could be extended to consider certain types of multinational enterprise in which the firms are thought of as subsidiaries owned by a 'parent' who chooses the location of each subsidiary to maximize profits. However, such an extension would not change the basic insights of our model. Gresik (2001) reviews the literature on taxing multinational firms; see also Bond and Gresik (1996) and Mintz and Smart (2004).

${ }^{9}$ In principle a firm at $s \in[0,1]$ might be able to change its technology to another position in the $[0,1]$ interval. Perhaps it could make an investment that enabled it to make better use of the public good. While this possibility is interesting, we do not analyze it in the present paper.

For some types of public goods such as intellectual property protection it is more appropriate to think of the public good as reducing the ex ante expected cost of production. Although our model is deterministic, this interpretation is broadly consistent with our analytical framework.

${ }^{10}$ This feature could be modeled in a more realistic way by, for example, making the value of $k$ country specific. However, the symmetry of $k$ across firms facilitates clearer insights concerning the introduction of, and increase in, variation of public good requirements across firms.
} 
specification, use of the public good generates no congestion externalities within the country and no spillovers to other countries. ${ }^{11}$ For a given increase in public good provision, the further a firm is to the right of the $[0,1]$ interval the greater is the cost-reducing impact of the public good on the firm's production.

Each firm is able to sell its single unit at price $p$ and has a fixed per-unit cost, $c$, that is independent of public good provision. If the firm at $s$ locates in country $i$ it must pay a tax $\tau_{i}$. The tax can be thought of as a lump sum tax or a sales tax (since each firm produces and sells only a single unit of the good). The profit function for the firm at $s$ is thus given by

$$
\pi_{s}=p-c-\tau_{i}+s k x_{i}{ }^{\theta}
$$

To focus the analysis on location decisions we shall assume that $p-c$ is fixed at a sufficiently high level for all firms to make non-negative profits no matter where they locate. ${ }^{12}$

For now, assume $k>0$. If $x_{A} \neq x_{B}$ then without loss of generality we assume that $x_{A}<x_{B} \cdot{ }^{13}$ In that case a firm may find it profitable to locate in the country with higher taxes if the cost reducing effect of the public good dominates.

For given $\tau_{A}, \tau_{B}, x_{A}$ and $x_{B}$ we can calculate the position in technology space $[0,1]$ of the marginal firm $\hat{s}$ that is just indifferent between locating in $A$ and $B$. That is, the firm $\hat{s}$ makes the same profits in either country;

$$
\tau_{A}-\hat{s} k x_{A}^{\theta}=\tau_{B}-\hat{s} k x_{B}^{\theta}
$$

Then $\hat{s}$ also determines the share of firms in $A$ and $1-\hat{s}$ gives the share of firms in $B$. We impose the necessary restrictions to ensure that the marginal firm must belong to the $[0,1]$

\footnotetext{
${ }^{11}$ Congestion costs are introduced to the model and analyzed in Appendix A2. While congestion costs have a quantitative effect on the efficient and equilibrium outcomes, they do not affect the qualitative characterization of the results. So in the body of the paper we present our results using the simpler framework without congestion costs.

${ }^{12}$ The price that each firm receives for the good that it sells could be made to vary across firms without affecting the results.

${ }^{13}$ In Section 4.2 we will show that there exists a unique subgame perfect equilibrium in which one government must set a higher level of public good provision than the other. Then $x_{A}<x_{B}$ is just a choice of labeling.
} 
interval. First, solve the above expression for $\hat{s}$ and hence define the function ${ }^{14}$

$$
\hat{s}\left(\tau_{A}, \tau_{B}, x_{A}, x_{B}\right)=\frac{\tau_{B}-\tau_{A}}{k\left(x_{B}^{\theta}-x_{A}{ }^{\theta}\right)} .
$$

Then $\hat{s}$, the share of firms in Country $A$, is defined as follows:

$$
\hat{s}=\left\{\begin{aligned}
\hat{s}\left(\tau_{A}, \tau_{B}, x_{A}, x_{B}\right) \text { if } \hat{s}\left(\tau_{A}, \tau_{B}, x_{A}, x_{B}\right) \in[0,1] \\
1 \text { if } \hat{s}\left(\tau_{A}, \tau_{B}, x_{A}, x_{B}\right)>1 \\
0 \text { if } \hat{s}\left(\tau_{A}, \tau_{B}, x_{A}, x_{B}\right)<0
\end{aligned}\right.
$$

If $\left(\tau_{B}-\tau_{A}\right) / k\left(x_{B}{ }^{\theta}-x_{A}{ }^{\theta}\right) \in[0,1]$ it is easy to check that all firms $s \in[0, \hat{s})$ make higher profits in $A$ than in $B$ and all firms $s \in(\hat{s}, 1]$ make higher profits in $B$ than in $A$. For the firms $s \in(\hat{s}, 1]$, the difference in the $\operatorname{tax} \tau_{B}-\tau_{A}$ is dominated by the lower costs brought about by higher public good provision. Clearly, the higher is $\tau_{B}$ the smaller is the share of firms that finds it profitable to locate in $B$.

If $x_{A}=x_{B}$ or $k=0$ then $\hat{s}$ as given by (2.2) is undefined. However, $x_{A}=x_{B}$ implies that the public good offered by the governments is homogeneous, and so firms can be thought of as responding in the manner of consumers in a Bertrand price setting game. If firms do not value the public good $(k=0)$, even if $x_{A} \neq x_{B}$, either government can attract all firms to its country by setting a slightly lower tax than the other government. In both cases we borrow the usual Bertrand assumptions to define the distribution of firms between countries. If $x_{A}=x_{B}$ or $k=0$ then all firms locate in the country with the lowest taxes:

$$
\hat{s}=\left\{\begin{array}{l}
0 \text { if } \tau_{A}<\tau_{B} \\
1 \text { if } \tau_{A}>\tau_{B} \\
\frac{1}{2} \text { if } \tau_{A}=\tau_{B}
\end{array}\right.
$$

We will refer to this case as Bertrand tax competition. The outcome of Bertrand tax competition will be used to define our benchmark case of intense tax competition.

The rents to office, $r_{A}$, of Government $A$ are given by the function $r_{A}=\tau_{A} \hat{s}-x_{A}$. The rents to office, $r_{B}$, of Government $B$ are given by $r_{B}=\tau_{B}(1-\hat{s})-x_{B}$. All policy variables take non-negative values. From the rent functions it is evident that the level of public good provision by a government also determines its cost; a level of public good provision $x_{i}$ costs $x_{i}$ to provide. In cases where $\hat{s}$ is defined by $(2.2), r_{A}\left(\tau_{A}, \tau_{B}\right)$ and $r_{B}\left(\tau_{A}, \tau_{B}\right)$ are given as

\footnotetext{
${ }^{14}$ Parameter values $k$ and $\theta$ will be suppressed throughout from general functional notation.
} 
follows:

$$
\begin{aligned}
& r_{A}\left(\tau_{A}, \tau_{B}, x_{A}, x_{B}\right)=\frac{\tau_{A}\left(\tau_{B}-\tau_{A}\right)}{k\left(x_{B}^{\theta}-x_{A}^{\theta}\right)}-x_{A} \\
& r_{B}\left(\tau_{A}, \tau_{B}, x_{A}, x_{B}\right)=\tau_{B}\left(1-\frac{\left(\tau_{B}-\tau_{A}\right)}{k\left(x_{B}^{\theta}-x_{A}^{\theta}\right)}\right)-x_{B} .
\end{aligned}
$$

Otherwise, in situations were $\hat{s}=0, r_{A}=-x_{A}$ and $r_{B}=\tau_{B}-x_{B}$ and where $\hat{s}=1$, $r_{A}=\tau_{A}-x_{A}$ and $r_{B}=-x_{B}$. No side-payments are allowed. ${ }^{15}$

To summarize, in terms of their technological requirements for public good provision, firms' positions are fixed in the interval $s \in[0,1]$, but each firm is able to choose its preferred country to maximize profits. Each government, on the other hand, is able to choose its level of taxation and public good provision but obviously its country ( $A$ or $B$ ) is fixed.

\section{Efficiency}

In this section we adapt a standard definition of efficiency to the context of the present model. The notion of efficiency determines the maximum level of surplus available for distribution to the agents in the model.

Definition 1. A plan, consisting of a public good allocation $\mathbf{x}^{E}=\left(x_{A}^{E}, x_{B}^{E}\right) \in \mathbb{R}_{+}^{2}$ and a share of firms $\hat{s}^{E} \in[0,1]$, is efficient if, for all other public good levels $\mathbf{x}=\left(x_{A}, x_{B}\right) \in \mathbb{R}_{+}^{2}$ and shares of firms $\hat{s} \in[0,1]$, it holds that

$$
\begin{aligned}
& r_{A}\left(\tau_{A}, \tau_{B}, x_{A}^{E}\right)+r_{B}\left(\tau_{A}, \tau_{B}, x_{B}^{E}\right)+\int_{0}^{\hat{s}^{E}} \pi_{s}\left(\tau_{A}, x_{A}^{E}\right) d s+\int_{\hat{s}^{E}}^{1} \pi_{s}\left(\tau_{B}, x_{B}^{E}\right) d s \\
\geq & r_{A}\left(\tau_{A}, \tau_{B}, x_{A}\right)+r_{B}\left(\tau_{A}, \tau_{B}, x_{B}\right)+\int_{0}^{\hat{s}^{3}} \pi_{s}\left(\tau_{A}, x_{A}\right) d s+\int_{\hat{s}}^{1} \pi_{s}\left(\tau_{B}, x_{B}\right) d s .
\end{aligned}
$$

Under Definition 1, a plan is efficient if it entails the largest possible surplus for division between the two governments and the firms. The planner's problem can be simplified to

$$
\max _{\hat{s}, x_{A}, x_{B}} \Omega\left(\hat{s}, x_{A}, x_{B}\right)=(p-c)-x_{A}-x_{B}+\frac{k}{2}\left(x_{B}^{\theta}-\hat{s}^{2}\left(x_{B}^{\theta}-x_{A}^{\theta}\right)\right) .
$$

\footnotetext{
${ }^{15} \mathrm{~A}$ 'partial equilibrium' interpretation is given to the assumption that governments can make negative rents; either that the model focuses on specific sectors within a larger economy, or that there is an unmodeled international capital market from which governments can borrow. We do not give greater prominence to this point because governments make positive rents in equilibrium.
} 
The first term, $(p-c)$, measures the net private revenues across all firms. These revenues are independent of the levels of public good provision. The terms $-x_{A}$ and $-x_{B}$ reflect the costs (to society) of providing the public good in each of the countries. The first term in the parentheses, $x_{B}{ }^{\theta}$, reflects the impact on total output across all firms if all firms locate in $B$. The second term in the parentheses reflects the loss of total surplus that results if a proportion $\hat{s}$ of firms locates in $A$. This loss comes about because, for all firms, output is increasing in public good provision and public good provision is lower in $A$ than in $B$. Since the taxes are just transfers between the firms and the governments, they drop out of the planner's problem.

We will now characterize efficiency in our first result. ${ }^{16}$

Proposition 1. In an efficient plan, $x_{A}^{E}=0$ and $x_{B}^{E}=\left(\frac{1}{2} \theta k\right)^{\frac{1}{1-\theta}}$. If $k>0$ then $\hat{s}^{E}=0$; the efficient plan is unique. If $k=0$ then $\hat{s}^{E}$ can take any value $\hat{s}^{E} \in[0,1]$.

If $k>1$ then the level of public good provision is higher in one country than the other. It is efficient for the planner to only provide the public good in one country and allocate all firms to that country; $\hat{s}^{E}=0 .{ }^{17}$ By comparison, if $k=0$ then in the efficient solution there is no public good provision and because countries are identical the share of firms that locates in each country is indeterminate.

\section{Competition in Taxes and Public Good Provision}

In this section we examine the outcome of competition for firms between governments within the framework of a two-stage game of fiscal competition. In Stage 1 of the game, the two governments noncooperatively and simultaneously choose (as pure strategies) levels of public good provision $x_{A} \in \mathbb{R}_{+}$and $x_{B} \in \mathbb{R}_{+}$respectively. Then in Stage 2 the governments, having observed the levels of public good provision, choose (as pure strategies) levels of taxation

\footnotetext{
${ }^{16}$ The proofs of all results are contained in Appendix A1.

${ }^{17}$ In the presence of congestion costs, $\hat{s}^{E}>0$. Since, to minimize congestion costs, the planner allocates some firms to $A$, it is also efficient to allocate a positive level of the public good there; $x_{A}^{E}>0$. However, the qualitative characterization of the efficient solution remains the same with congestion costs in the sense that $x_{B}^{E}>x_{A}^{E}$ even as the congestion cost becomes large. The reason is that the most productive firms are allocated to $B$ and it is therefore efficient to allocate a higher level of public good provision to that country.
} 
$\tau_{A} \in \mathbb{R}_{+}$and $\tau_{B} \in \mathbb{R}_{+}$respectively. This order of events is regarded to reflect the idea that taxes can be changed relatively easily once the level of public good provision has been chosen, while a change in the level of public good provision requires modification of the infrastructure through which it is provided. ${ }^{18}$ Once the governments' decisions have been taken, firms take taxes and levels of public good provision as given and choose their geographical locations (i.e. $A$ or $B$ ) to maximize profits. We refer to this whole process, including both stages, as a tax competition game and we solve for an equilibrium in taxes and public good provision using backwards induction. ${ }^{19}$

\subsection{Stage 2: The Tax Subgame}

We will next solve for Stage 2, where the levels of public good provision by the two governments are taken as fixed at (non-negative) levels $x_{A}$ and $x_{B}$.

For given levels of public good provision $x_{A}$ and $x_{B}$, a strategy $\tau_{A}^{*}$ of Government $A$ is a best-response tax against a strategy $\tau_{B}$ when it maximizes $r_{A}\left(\tau_{A}, \tau_{B}\right)$. Government A's best-response tax function is written as $T_{A}\left(\tau_{B}\right)$ with Government $B$ 's best-response tax function being written analogously as $T_{B}\left(\tau_{A}\right)$. A Nash equilibrium in taxes is a pair $\left(\tau_{A}^{*}, \tau_{B}^{*}\right)$ for which $\tau_{A}^{*}$ is a best-response to $\tau_{B}^{*}$ and vice-versa. ${ }^{20}$

We will start with the case where $x_{A}<x_{B}$. We need the following lemma to establish best-response tax functions in this situation.

\footnotetext{
${ }^{18}$ It will be assumed throughout that mixed strategies in tax rates are not available to governments. This is generally deemed to be an acceptable assumption in the applied literature on policy setting in a perfectinformation environment. For example (except in part of one result where a pure strategy equilibrium does not exist) Justman et al (2002) consider only pure strategies in their model of fiscal competition.

${ }^{19}$ We are not the first to model interjurisdictional competition in tax and spending levels as a two stage game; this approach has been taken previously by Hoyt and Jensen (2001) among others. As Kreps and Scheinkman (1983) argue in their study of firm behavior, the appropriateness of the set-up, or the game context, is essentially an empirical matter. Certainly, it seems reasonable to argue that levels of public good provision are more difficult to change than taxes and so these are set in the first stage because governments can more easily commit to them. This parallels the familiar argument that firms can more easily commit to production capacity than prices. Then in the second stage governments announce taxes in the same way that firms announce prices.

${ }^{20}$ Note that $\tau_{A}$ denotes a particular strategy of Government $A$, whereas $T_{A}$ denotes its best-response.
} 
Lemma 1. Assume that $x_{A}$ and $x_{B}$ are fixed, with $0 \leq x_{A}<x_{B}$. For given $\tau_{B}$, Government $A$ 's best-response tax function is

$$
T_{A}\left(\tau_{B}\right)=\frac{\tau_{B}}{2}
$$

For given $\tau_{A}$, Government B's best-response tax function is

$$
T_{B}\left(\tau_{A}\right)=\frac{\tau_{A}}{2}+\frac{k\left(x_{B}^{\theta}-x_{A}^{\theta}\right)}{2} .
$$

The best-response tax functions are illustrated in Figure 1. We see that, for fixed levels of public goods, optimal tax rates are strategic complements. We will now discuss the properties of these functions, as this will help us to understand how the intensity of tax competition is determined in Proposition 2 below.

Government $A$ 's best-response function is derived by rearranging the first order condition for the maximization of $r_{A}$. The function shows that Government $A$ 's best-response tax depends only on the level of $\tau_{B}$. Government $B$ 's best-response function is more interesting because it helps us to see the underlying mechanism through which the intensity of tax competition is reduced. For any $\tau_{A}$, the level of $\tau_{B}$ that maximizes $r_{B}$ is increasing in $k$. To see why, look at the first order condition for maximization of $r_{B}$;

$$
\begin{aligned}
\frac{d r_{B}}{d \tau_{B}} & =1-\hat{s}-\tau_{B} \frac{\partial \hat{s}}{\partial \tau_{B}} \\
& =1-\frac{\tau_{B}-\tau_{A}}{k\left(x_{B}{ }^{\theta}-x_{A}{ }^{\theta}\right)}-\frac{\tau_{B}}{k\left(x_{B}{ }^{\theta}-x_{A}{ }^{\theta}\right)}=0
\end{aligned}
$$

From the first order condition it is easy to see that $r_{B}$ is strictly concave. It also becomes clear that $d r_{B} / d \tau_{B}$ is increasing in $k$. Look first at $\hat{s}$; the second term in the expression above. Assuming values of $\tau_{A}, \tau_{B}$, and $x_{A}<x_{B}$ that imply $\hat{s} \in(0,1)$,

$$
\frac{\partial \hat{s}}{\partial k}=-\frac{\tau_{B}-\tau_{A}}{k^{2}\left(x_{B}^{\theta}-x_{A}^{\theta}\right)}=-\frac{\hat{s}}{k}<0 .
$$

An increase in $k$ results in a decrease in $\hat{s}$. Intuitively, the greater the positive impact of the public good on profits, the higher Government $B$ can set its $\operatorname{tax} \tau_{B}$ above $\tau_{A}$ and still attract a given share of firms $1-\hat{s}$ to its country. ${ }^{21}$

\footnotetext{
${ }^{21}$ The parameter $\theta$ affects the impact of the public good on profits in a similar but more complex way. This will be discussed further below.
} 
Differentiating the third term of the first order condition w.r.t. $k$, we see that

$$
\frac{\partial^{2} \hat{s}}{\partial \tau_{B} \partial k}=-\frac{1}{k^{2}\left(x_{B}^{\theta}-x_{A}{ }^{\theta}\right)}<0 .
$$

So if Government $B$ increases its tax this induces firms to move to $A$, i.e. $\partial \hat{s} / \partial \tau_{B}=$ $\left(k\left(x_{B}{ }^{\theta}-x_{A}{ }^{\theta}\right)\right)^{-1}$, but this effect is dampened by an increase in $k$. For higher $k$, Government $B$ 's loss in share of firms due to an increase in $\tau_{B}$ is more limited. It is due to these two combined effects that an increase in $k$ increases Government $B$ 's best response tax for any given $\tau_{A}$; the difference in equilibrium tax levels increases as a result of an increase in $k$.

In the next result, the outcome of Bertrand tax competition $\left(k=0\right.$ or $\left.x_{A}=x_{B}\right)$ gives us our benchmark. Against this we compare the outcome of tax competition when firms care about the level of public good provision $(k>0)$ and public good levels are differentiated $\left(x_{B}>x_{A}\right)$. It will come as no surprise that the difference between taxes is minimized under Bertrand tax competition; this case is included in the result for completeness. The outcome under Bertrand tax competition is referred to as intense tax competition. If in equilibrium there is a greater difference between taxes than in the benchmark case, we will say that that the intensity of tax competition is reduced relative to Bertrand tax competition.

Proposition 2. (The intensity of tax competition.) Assume that $x_{A}$ and $x_{B}$ are fixed.

For $x_{A}=x_{B}$ or for $k=0$ (Bertrand tax competition), there exists a unique subgame equilibrium point in taxes for which $\tau_{A}^{*}=\tau_{B}^{*}=0$ and $\hat{s}=\frac{1}{2}$.

For $x_{A} \neq x_{B}$ and $k>0$ assume that $x_{A}<x_{B}$. Then there exists a unique subgame equilibrium point in taxes for which $\tau_{A}^{*}\left(x_{A}, x_{B}\right)<\tau_{B}^{*}\left(x_{A}, x_{B}\right)$ :

$$
\tau_{A}^{*}\left(x_{A}, x_{B}\right)=\frac{1}{3} k\left(x_{B}{ }^{\theta}-x_{A}{ }^{\theta}\right) ; \tau_{B}^{*}\left(x_{A}, x_{B}\right)=\frac{2}{3} k\left(x_{B}{ }^{\theta}-x_{A}{ }^{\theta}\right) ; \hat{s}=1 / 3 .
$$

The larger is $k$, the more the intensity of tax competition is reduced.

If $x_{A}=x_{B}$ or $k=0$ then Bertrand tax competition brings about an equilibrium outcome in which $\tau_{A}^{*}=\tau_{B}^{*}=0$; tax competition is intense. Because $x_{A}$ is sunk, for any positive tax level it is a dominant strategy for each government to undercut the other in setting taxes and in doing so attract all firms to its country. By assumption, if $\tau_{A}^{*}=\tau_{B}^{*}=0$ then $\hat{s}=\frac{1}{2}$. 
Because taxes are zero the share of firms that locates in each country makes no difference to rents; thus $r_{A}=r_{B}=-x_{A}$.

If $k>0$ then the difference between $\operatorname{tax} \tau_{A}^{*}\left(x_{A}, x_{B}\right)$ and $\tau_{B}^{*}\left(x_{A}, x_{B}\right)$ is proportional to the difference between $x_{B}$ and $x_{A}$ and the size of $k ; \tau_{B}^{*}-\tau_{A}^{*}=k\left(x_{B}{ }^{\theta}-x_{A}{ }^{\theta}\right) / 3$. The intensity of tax competition is reduced relative to Bertrand tax competition; the extent to which the intensity of tax competition is reduced is proportional to the size of $k$. These features of the equilibrium are seen from Figure 1, which shows that the intercept of Government B's best-response function $T_{B}\left(\tau_{A}\right)$ is increasing in $x_{B}{ }^{\theta}-x_{A}{ }^{\theta}$ and $k$. Consequently, the equilibrium tax levels $\tau_{A}^{*}$ and $\tau_{B}^{*}$ increase as either $x_{B}{ }^{\theta}-x_{A}{ }^{\theta}$ or $k$ is increased.

Intuitively, the reduction in the intensity of tax competition for $k>0$ is based on the fact that, as $x_{A}$ is reduced relative to $x_{B}$, Country $A$ becomes less attractive to firms that locate in $B$. So Government $B$ is able to raise its tax, making higher rents from each firm while holding its share of firms constant. At the same time, this makes Country $B$ less attractive to firms in $A$, so Government $A$ is able to raise its tax and make higher rents from each firm while holding its share of firms constant.

It is interesting to note that the share of firms locating in Country $B$ is relatively large, at $1-\hat{s}=2 / 3$, even though $B$ sets a higher tax in equilibrium. We might have expected to see the high-tax country attracting a relatively small share of firms but this is not the case. A higher level of public good provision can have a cost-reducing impact sufficiently large as to make location in Country $B$ more profitable for a majority of firms, despite higher taxation there. ${ }^{22}$

\subsection{Stage 1: Level of public good provision}

In solving for the level of public good provision by the respective governments, we must drop the assumption that $x_{A} \leq x_{B}$. In looking for Government $A$ 's best response to $x_{B}$, we must

\footnotetext{
${ }^{22}$ For given levels of public good provision, the introduction of congestion costs to our model does not affect the intensity of tax competition. This is because they make the levels of taxation higher in both countries but do not affect the difference across countries. Congestion costs do affect the intensity of tax competition through their impact on the levels of public good provision; we will comment on this in the next subsection.
} 
evaluate $r_{A}\left(x_{A}, x_{B}\right)$ for $x_{A}<x_{B}, x_{A}=x_{B}$ and $x_{A}>x_{B}$. The same applies for $B$.

Using the equilibrium values for $\tau_{A}^{*}$ and $\tau_{B}^{*}$ from Proposition 2 in $r_{A}=\tau_{A} \hat{s}-x_{A}$, Government $A$ 's rent function is defined as follows:

$$
r_{A}\left(x_{A}, x_{B}\right)=\left\{\begin{array}{c}
k\left(x_{B}{ }^{\theta}-x_{A}{ }^{\theta}\right) / 9-x_{A} \text { if } 0 \leq x_{A}<x_{B} \\
-x_{A} \text { if } 0 \leq x_{A}=x_{B} \\
4 k\left(x_{A}{ }^{\theta}-x_{B}{ }^{\theta}\right) / 9-x_{A} \text { if } 0 \leq x_{B}<x_{A} .
\end{array}\right.
$$

For Government $B$,

$$
r_{B}\left(x_{A}, x_{B}\right)=\left\{\begin{array}{c}
4 k\left(x_{B}^{\theta}-x_{A}{ }^{\theta}\right) / 9-x_{A} \text { if } 0 \leq x_{A}<x_{B} \\
-x_{B} \text { if } 0 \leq x_{A}=x_{B} \\
k\left(x_{A}{ }^{\theta}-x_{B}{ }^{\theta}\right) / 9-x_{B} \text { if } 0 \leq x_{B}<x_{A} .
\end{array}\right.
$$

A level of public good provision $x_{A}^{*}$ of Government $A$ is a best response against a level of public good provision $x_{B}$, denoted $B R_{A}\left(x_{B}\right)$, when it maximizes $r_{A}\left(x_{A}, x_{B}\right)$. A Nash equilibrium in levels of public good provision is a pair $\left(x_{A}^{*}, x_{B}^{*}\right)$ where $x_{A}^{*}$ is a best response against $x_{B}^{*}$ and vice-versa.

We will now state our existence-and-characterization-of-equilibrium result.

Proposition 3. (The unique asymmetric equilibrium.) Assume that governments play a tax competition game, with $k>0$.

1. There exists a unique subgame perfect equilibrium in pure strategies.

2. The equilibrium has the property that one country, say A, provides a smaller amount of the public good than the other, $B$.

3. The subgame perfect equilibrium is determined uniquely by the values:

$$
x_{A}^{*}=0 ; x_{B}^{*}=\left(\frac{4}{9} \theta k\right)^{\frac{1}{1-\theta}} ; \tau_{A}^{*}=\frac{1}{3} k\left(\frac{4}{9} \theta k\right)^{\frac{\theta}{1-\theta}} ; \tau_{B}^{*}=\frac{2}{3} k\left(\frac{4}{9} \theta k\right)^{\frac{\theta}{1-\theta}} ; \hat{s}=\frac{1}{3} .
$$

4. In the (pure strategies) subgame perfect equilibrium public good provision in Country $B$ is inefficiently low: $x_{B}^{E}=\left(\frac{1}{2} \theta k\right)^{\frac{1}{1-\theta}}>x_{B}^{*}=\left(\frac{4}{9} \theta k\right)^{\frac{1}{1-\theta}}$.

Proposition 3 shows that while Country $B$ provides the public good at a positive level, $A$ provides none at all. Also note that, although taxation is higher in $B$ than in $A$, taxation in $A$ is nevertheless positive. Thus Country $A$ has a degree of monopoly power and is able 
to collect rents due to the fact that firms must locate in one country or the other in order to produce. Finally, the result shows that the equilibrium level of public good provision is inefficient. $^{23}$

In Section 4.1 we argued that tax competition becomes less intense the greater the difference between $x_{B}$ and $x_{A}$, which suggests that Government $A$ has an incentive to reduce $x_{A}$ relative to $x_{B}$ in Stage 1 so that it can raise taxes in Stage 2. Proposition 3 shows formally that this effect does indeed operate to the point where Government $A$ provides no public goods at all. It seems reasonable to argue that such an effect would operate under more general specifications than ours, although for more complex models public good provision may not be driven all the way to zero in $A$.

Proposition 3 also shows that in equilibrium the opposing forces on $x_{B}$ balance at a positive level $x_{B}^{*}=\left(\frac{4}{9} \theta k\right)^{\frac{1}{1-\theta}}$. Tax competition is less intense when $x_{B}$ is increased, enabling Government $B$ to raise $\tau_{B}$ while holding its share of firms constant, potentially increasing rents. But of course this increases the cost of provision, which works on rents in the opposite direction. The effect of a change in $k$ is clear. As $k$ is increased this brings about an increase in $x_{B}^{*}$ because public good provision has a bigger impact on firms' profits and therefore on government rents through taxation.

It is easy to check that both governments make positive rents in equilibrium. For Country $A$ this is immediately obvious because it collects taxes from a positive share of firms but has no costs of public good provision. For Country $B$ we use the equilibrium values for $\tau_{B}^{*}$ and $x_{B}^{*}$ in the expression for Government $B$ 's rents to obtain, in reduced form, $r_{B}=$ $\left(\frac{4 k}{9}\right)^{\frac{1}{1-\theta}}\left[\theta^{\frac{\theta}{1-\theta}}-\theta^{\frac{1}{1-\theta}}\right]$. To see that $r_{B}>0$ for all $\theta \in(0,1)$ note that $\lim _{\theta \rightarrow 0} \theta^{\frac{\theta}{1-\theta}}=1$ while $\lim _{\theta \rightarrow 0} \theta^{\frac{1}{1-\theta}}=0$ and $\lim _{\theta \rightarrow 1} \theta^{\frac{\theta}{1-\theta}}=\lim _{\theta \rightarrow 1} \theta^{\frac{1}{1-\theta}}=1 / e$, with $\theta^{\frac{\theta}{1-\theta}}$ decreasing monotonically from 1 to $1 / e$ as $\theta$ is varied from 0 to 1 , and $\theta^{\frac{1}{1-\theta}}$ increasing monotonically from 0 to $1 / e$ as $\theta$ is varied from 0 to 1 . This makes intuitive sense if we think of the outcome as oligopolistic, where both governments are able to choose quantities and prices (here taxes) at which they

\footnotetext{
${ }^{23}$ In the proof we show that the equilibrium in pure strategies must be asymmetric in that one government sets public good provision above the level of the other. We prove that this equilibrium exists and is unique subject to a re-labeling of countries. We then choose to label Countries $A$ and $B$ as before, as the countries of low and high level public good provision respectively.
} 
make non-negative rents. ${ }^{24}$

We can now determine which government makes higher rents. Using equilibrium values from Proposition 3, we know that $r_{A}=\frac{k}{9}\left(\frac{4 \theta k}{9}\right)^{\frac{\theta}{1-\theta}}$ and $r_{B}=\left(\frac{4 k}{9}\right)^{\frac{1}{1-\theta}}\left[\theta^{\frac{\theta}{1-\theta}}-\theta^{\frac{1}{1-\theta}}\right]$. From this we have that $r_{A} \gtrless r_{B}$ if and only if $\frac{1}{4 \theta}\left(\frac{4 \theta k}{9}\right)^{\frac{1}{1-\theta}} \gtrless\left(\frac{1}{\theta}-1\right)\left(\frac{4 \theta k}{9}\right)^{\frac{1}{1-\theta}}$ or, equivalently, if and only if $\theta \gtrless \frac{3}{4} \cdot{ }^{25}$

Finally, and this is a point worth noting, we are now able to see why the level of public good provision is suboptimal under tax competition. More firms locate in Country $A$ under tax competition than under efficiency. As a result, the marginal benefit to a policysetter of providing the public good is lower, whether this policy-setter is the planner or the government. If $\tau_{A}=\tau_{B}$ were arbitrarily fixed at Stage 2, then Government B's incentive to set $x_{B}$ is identical to that of the planner, and it would set $x_{B}=x_{B}^{E}$. Conversely, if the planner were constrained to set taxes $\tau_{A}^{*}=\frac{1}{3} k\left(\frac{4}{9} \theta k\right)^{\frac{\theta}{1-\theta}}$ and $\tau_{B}^{*}=\frac{2}{3} k\left(\frac{4}{9} \theta k\right)^{\frac{\theta}{1-\theta}}$, the outcome of tax competition, then the planner's solution to the level of public good provision would be $x_{B}=x_{B}^{*}$.

As a final point, note that both $x_{B}^{E}$ and $x_{B}^{*}$ go to 0 as $k$ goes to 0 . This is plausible since the public good becomes less effective at saving costs as $k$ tends to zero so no firm will pay for it, and so no country will (or should) provide it. Thus, as the public good becomes less effective across the distribution at reducing firms' costs, and consequently as tax competition becomes more intense, the equilibrium of the tax competition game converges towards the efficient solution. ${ }^{26}$

\footnotetext{
${ }^{24} \mathrm{We}$ conjecture that this property, governments making positive rents in equilibrium, would hold for a more general specification of the profit function in that the term $k x_{i}{ }^{\theta}$ could be replaced by a general function $b\left(x_{i} ; \theta, k\right)$, with $b(\cdot)$ concave in $x_{i}$ and $\partial b / \partial k>0$.

${ }^{25}$ The broader effects of changes in $\theta$ are not directly relevant to the focus of our analysis. However, they are discussed at length in Appendix A3.

${ }^{26}$ When congestion costs are introduced to the model, as they are increased this has the effect of bringing about a reduction both in $x_{B}^{E}$ and $x_{B}^{*}$. Also, with congestion $\operatorname{costs} x_{A}^{E}>x_{A}^{*}=0$; recall that without congestion costs $x_{A}^{E}=x_{A}^{*}=0$. As the congestion cost is increased, the (negative) effect on $x_{B}^{E}$ is larger than on $x_{B}^{*}$. More firms are induced to locate in $A$ both in the planner's solution and in equilibrium. But the effect is more muted under tax competition than under the planner's solution because governments care about their rents and not the overall social cost of congestion. So there exists a level of congestion costs at which $x_{B}^{E}=x_{B}^{*}$. But the solution is not efficient since the equilibrium share of firms across countries does not correspond to efficiency. And as congestion costs are increased equilibrium does not converge to efficiency; to the contrary, $x_{B}^{*}>x_{B}^{E}$ and $x_{A}^{E}>x_{A}^{*}$. We can thus see by inspection of $\tau_{B}^{*}-\tau_{B}^{*}=k\left(\left(x_{B}^{*}\right)^{\theta}-\left(x_{A}^{*}\right)^{\theta}\right) / 3$ that tax competition will not in general be intensified and may be reduced by congestion costs.
} 


\section{Policies of Tax Coordination}

The two most commonly advanced proposals for tax policy coordination are the setting of a minimum tax and tax harmonization. The context that we have in mind is the calls for tax coordination among the member states of the European Union (EU). We argue that the institutional arrangements put in place by the EU now make it possible to coordinate policy in a way that was not thought possible in the past. In this respect, the new institutional features may be interpreted as a political economy shock which introduces the possibility of policy coordination. We capture this situation formally with a new game where the levels of public goods are fixed at the equilibrium levels of Proposition 3 and are XXtaken as parametric. Governments are granted the opportunity to coordinate tax policy; this may be a minimum tax or tax harmonization. Governments then simultaneously and without communicating set their tax levels (subject to the constraints of the policy coordination). Finally, firm location is determined. Now that the overall framework has been set out, we will consider each tax coordination policy in turn, taking a minimum tax first.

\subsection{A Minimum Tax}

We examine the imposition of a minimum tax of the kind considered by Kanbur and Keen (1993). A minimum tax, $\mu$, is a level below which neither government is allowed to set its tax. Writing the respective levels of public good provision under the minimum tax constraint as $x_{A}^{\mu}$ and $x_{B}^{\mu}$, by assumption the levels of public good provision are fixed at the levels given by Proposition 3, that is, $x_{A}^{\mu}=x_{A}^{*}=0$ and $x_{B}^{\mu}=x_{B}^{*}=\left(\frac{4}{9} \theta k\right)^{\frac{1}{1-\theta}}$. Since without the minimum tax the equilibrium taxes would be as in Proposition 3, the minimum tax only imposes a binding constraint if $\mu \geq \tau_{A}^{*}$. On the other hand, $\mu$ can be set sufficiently high to ensure that tax rates are equalized. By inspection of (2.2), it is clear that if the constraint sets a

minimum that implies $\tau_{A}=\tau_{B}$ then all firms locate in Country $B$. Since rents for $A$ are zero if the share of firms that locates in $A$ is zero, a value of $\mu$ higher than the value required to ensure $\tau_{A}=\tau_{B}$ cannot yield higher rents for $A$ than with no minimum tax. Therefore, we may restrict attention to a value of $\mu$ that lies between $\tau_{A}^{*}$ and a value that ensures 
$\tau_{A}=\tau_{B} \cdot{ }^{27}$

Let $\mu$ be set at a level $\varepsilon$ above $A$ 's equilibrium tax under tax competition;

$$
\mu=\tau_{A}^{*}+\varepsilon=\frac{1}{3} k\left(x_{B}^{\theta}-x_{A}{ }^{\theta}\right)+\varepsilon, \varepsilon \geq 0 .
$$

Let $\tau_{A}^{\mu}$ be the tax that Government $A$ sets in the presence of the minimum tax. By the concavity of $r_{A}$ in $\tau_{A}$, the best Government $A$ can do in the presence of the minimum tax is to set $\tau_{A}^{\mu}=\mu$. The tax set by Government $B$ is determined by the best-response function $T_{B}\left(\tau_{A}\right)=\left(\tau_{A}+k\left(x_{B}{ }^{\theta}-x_{A}{ }^{\theta}\right)\right) / 2$ as $\tau_{B}^{\mu}=\frac{2}{3} k\left(x_{B}{ }^{\theta}-x_{A}{ }^{\theta}\right)+\frac{1}{2} \varepsilon$. We can now see that if $\varepsilon=\frac{2}{3} k\left(x_{B}{ }^{\theta}-x_{A}{ }^{\theta}\right)$, then $\tau_{A}^{\mu}=\tau_{B}^{\mu}$. Therefore, we restrict attention to $\varepsilon \in\left[0, \frac{2}{3} k\left(x_{B}{ }^{\theta}-x_{A}{ }^{\theta}\right)\right]$.

To agree upon a minimum tax, the governments must effectively agree upon a value for $\varepsilon$. We characterize the non-renegotiable minimum-tax-frontier as the set of minimum taxes (values of $\varepsilon$ ) for which: (i) neither government can obtain higher rent by a change in the minimum tax without the other government having to accept lower rent; (ii) both governments obtain higher rents than with no minimum tax. Given any minimum tax on the frontier, the two governments would not jointly agree to renegotiate to any other minimum tax or to abolish the minimum tax. ${ }^{28}$

Using $x_{A}^{\mu}=x_{A}^{*}=0, x_{B}^{\mu}=x_{B}^{*}=\left(\frac{4}{9} \theta k\right)^{\frac{1}{1-\theta}}, \tau_{A}^{\mu}=\mu=\tau_{A}^{*}+\varepsilon=\frac{1}{3} k\left(x_{B}^{\mu}\right)^{\theta}+\varepsilon$ and $\tau_{B}^{\mu}=\frac{2}{3} k\left(x_{B}^{\mu}\right)^{\theta}+\frac{1}{2} \varepsilon$ in the expressions for $\hat{s}, r_{A}$, and $r_{B}$, (that is 2.2, 4.2 and 4.3), we obtain the following reduced form expressions for government rents. To emphasize that rents are

\footnotetext{
${ }^{27}$ For reasons that will become clear, $\tau_{B}^{*}$ does not impose the upper bound on $\mu$, unlike in Kanbur and Keen (1993).

${ }^{28}$ More formally, the notion of a non-renegotiable minimum-tax-frontier corresponds to the set of strong Nash equilibria of a coordination game in which governments choose values of $\varepsilon$. In a strong Nash equilibrium neither government has an incentive, individually or collectively, to move to a different value of $\varepsilon$. In such a game the selection of differing values of $\varepsilon$ by the governments, either as an initial strategy or as a deviation, results in a disagreement on the minimum tax and implementation of the equilibrium of Proposition 3.

The notion of the non-renegotiable minimum-tax-frontier is related to the Pareto efficient frontier. The key difference is that the non-renegotiable minimum-tax-frontier is defined by the outcome of strategic interactions between the two governments and, as we shall see, is not Pareto efficient.
} 
being derived under the minimum tax, we shall write these as $r_{A}^{\mu}(\varepsilon)$ and $r_{B}^{\mu}(\varepsilon)$ respectively:

$$
\begin{aligned}
& r_{A}^{\mu}(\varepsilon)=\frac{1}{9} k\left(\frac{4}{9} \theta k\right)^{\frac{\theta}{1-\theta}}+\frac{1}{6} \varepsilon-\frac{\varepsilon}{2 k\left(\left(\frac{4}{9} \theta k\right)^{\frac{\theta}{1-\theta}}\right)} \\
& r_{B}^{\mu}(\varepsilon)=\frac{4}{9} k\left(\frac{4}{9} \theta k\right)^{\frac{\theta}{1-\theta}}-\left(\frac{4}{9} \theta k\right)^{\frac{1}{1-\theta}}+\frac{2}{3} \varepsilon+\frac{\varepsilon^{2}}{4 k\left(\frac{4}{9} \theta k\right)^{\frac{\theta}{1-\theta}}} .
\end{aligned}
$$

We now characterize the non-renegotiable minimum-tax-frontier.

Proposition 4. (The non-renegotiable minimum-tax-frontier.) Fix $k>0, x_{A}^{\mu}=0$ and $x_{B}^{\mu}=\left(\frac{4}{9} \theta k\right)^{\frac{1}{1-\theta}}$ and fix a minimum $\operatorname{tax} \mu=\frac{1}{3} k\left(x_{B}{ }^{\theta}-x_{A}{ }^{\theta}\right)+\varepsilon$. Then Government $A$ maximizes $r_{A}(\varepsilon)$ by setting $\tau_{A}^{\mu}=\frac{1}{3} k\left(\left(\frac{4}{9} \theta k\right)^{\frac{\theta}{1-\theta}}\right)+\varepsilon$ and Government $B$ maximizes $r_{B}(\varepsilon)$ by setting $\tau_{B}^{\mu}=\frac{2}{3} k\left(\left(\frac{4}{9} \theta k\right)^{\frac{\theta}{1-\theta}}\right)+\frac{1}{2} \varepsilon$. A minimum tax is on the non-renegotiable minimumtax-frontier iff $\varepsilon \in\left(\frac{1}{6} k\left(\frac{4}{9} k \theta\right)^{\frac{\theta}{1-\theta}}, \frac{1}{3} k\left(\frac{4}{9} k \theta\right)^{\frac{\theta}{1-\theta}}\right)$; in that case, both governments make higher rents than with no minimum tax and any change in the minimum tax yields strictly higher rents for one government but strictly lower rents for the other government. Any minimum tax for which $\varepsilon \in\left(0, \frac{1}{3} k\left(\frac{4}{9} k \theta\right)^{\frac{\theta}{1-\theta}}\right)$ increases efficiency.

Because public good provision is fixed at the levels given by Proposition 3, we are able to see the direct effect on taxes and hence rents of introducing the minimum tax. Using (2.2) it is possible to check that while $A$ benefits from being able to set higher taxes, it loses firms as $\varepsilon$ is increased. As $\varepsilon$ is increased above $\varepsilon=\frac{1}{6} k\left(\frac{4}{9} k \theta\right)^{\frac{\theta}{1-\theta}}$, the loss to $A$ from the migration of firms to $B$ is greater than the gain from being able to tax each firm at a higher rate. For $\varepsilon>\frac{1}{3} k\left(\frac{4}{9} k \theta\right)^{\frac{\theta}{1-\theta}}, A$ would make higher rents without a minimum tax than with one. ${ }^{29}$

The implications for efficiency of a minimum tax reported in Proposition 4 are easy to deduce using (2.2) and (3.1). First note that $x_{A}^{\mu}$ and $x_{B}^{\mu}$ are fixed. So, by inspection of (3.1), the only way that efficiency can change under the imposition of the minimum tax is by a change in $\hat{s}$. Since the imposition of the minimum tax reduces the difference between taxes, by (2.2), the share of firms that locates in $B$ increases with the minimum tax. Due

\footnotetext{
${ }^{29}$ In our model, if a minimum tax were applied in a setting where $k=0$ then this would (trivially) imply no change in efficiency. The reason is that in this case the countries would be identical in the equilibrium of Proposition $3\left(x_{A}^{\mu}=x_{B}^{\mu}=\tau_{A}^{\mu}=\tau_{B}^{\mu}=0\right)$ and the minimum tax, by raising taxes above zero, simply implies a (lump-sum) redistribution from firms to governments.
} 
to the fact that public good provision is higher in $B$, this increases efficiency. However, note that the imposition of the minimum tax does not increase Pareto efficiency because, while one or more governments is able to extract additional surplus through higher taxation, this is achieved at the expense of firms' profits (see the profit function of the firm 2.1; in it, $p-c$ and $x_{i}$ are fixed, while $\tau_{i}$ increases). This result accords with Kanbur and Keen's (1993) analysis, which shows that total surplus may be increased through the imposition of a minimum tax. ${ }^{30}$ But it adds the twist that the additional surplus generated by the minimum tax may be expropriated by self-seeking governments if they have to power to achieve this. ${ }^{31}$

\subsection{Tax Harmonization}

We consider tax harmonization that restricts taxes in such a way that it moves them towards the levels that would bring about an efficient outcome, as in Mintz and Tulkens (1996) for example. To find the taxes that would bring about an efficient outcome, consider a less general planning problem than the one set out in Section 3 in which the planner chooses taxes for each country instead of an allocation of firms, and firms then choose locations based on (2.2). It is easy to see that, since the efficient solution entails an outcome in which all firms locate in one country, the planner could achieve this solution by setting taxes equal across the two countries. ${ }^{32}$ This is equivalent to 'split the difference' tax harmonization used by Baldwin and Krugman (2004) among others. It is different from a minimum tax in the sense that it imposes a ceiling as well as a floor to the level of taxation. ${ }^{33}$

The tax harmonization regime that we consider does not necessarily result in complete equalization of taxes. Instead, in addition to the floor that is put in place under the minimum tax, a ceiling is put in place as well. We will denote harmonized taxes in countries $A$ and $B$ by $\tau_{A}^{h}$ and $\tau_{B}^{h}$ respectively. Following on from our formalization of the minimum tax, define

\footnotetext{
${ }^{30}$ Note that full efficiency cannot be achieved because $x_{B}^{\mu}$ is fixed at $x_{B}^{*}$.

${ }^{31}$ We have not formally analyzed the effect of a minimum tax in the presence of congestion costs but intuitively the logic of Proposition 4 extends to that setting too.

${ }^{32}$ See Zissimos and Wooders (2006) for a full statement of the planner's problem in this form.

${ }^{33}$ Tax harmonization is formalized as a coordination game between the governments wherein there is (simultaneous) coordination not just on a minimum tax but on a maximum tax as well.
} 
harmonized taxes as follows:

$$
\begin{aligned}
\tau_{A}^{h} & =\tau_{A}^{*}+\varepsilon=\frac{1}{3} k\left(x_{B}{ }^{\theta}-x_{A}{ }^{\theta}\right)+\varepsilon \\
\tau_{B}^{h} & =\tau_{B}^{*}-\alpha \varepsilon=\frac{1}{3} k\left(x_{B}{ }^{\theta}-x_{A}{ }^{\theta}\right)-\alpha \varepsilon, \alpha, \varepsilon \geq 0 .
\end{aligned}
$$

A given choice of $\varepsilon$ increases $\tau_{A}^{h}$ and reduces $\tau_{B}^{h}$ relative to their respective equilibrium values without tax harmonization. The presence of the parameter $\alpha$ means that the constraints of harmonization do not have to bind equally across countries. Indeed, if $\alpha=0$ then the harmonization constraint simply prevents $B$ from raising its tax while the constraint mandates an increase of $A$ 's tax. For a large value of $\alpha$, the harmonization constraint mandates a larger reduction of $B$ 's tax then it does an increase of $A$ 's tax. Solving for the value of $\varepsilon$ at which $\tau_{A}^{h}=\tau_{B}^{h}$ we obtain $\varepsilon=k\left(x_{B}{ }^{\theta}-x_{A}{ }^{\theta}\right) /(3(1+\alpha))$. We will restrict attention to $\varepsilon \in\left[0, k\left(x_{B}{ }^{\theta}-x_{A}{ }^{\theta}\right) /(3(1+\alpha))\right]$.

From (3.1), efficiency-maximizing tax harmonization would involve a complete equalization of tax rates; $\varepsilon=k\left(x_{B}{ }^{\theta}-x_{A}{ }^{\theta}\right) /(3(1+\alpha))$; this corresponds to intense tax competition, with the emphasis not on the fact that taxes are set to zero but on the fact that they are equalized. A key difference is that under efficiency-maximizing tax harmonization all firms locate in Country $B$. Rents collected by $B$ increase while rents collected by $A$ decrease. The level of efficiency is higher than under the minimum tax because all firms locate in $B$, where public good provision is higher, while under the minimum tax some firms locate in $A$.

The fact that efficiency-maximizing tax harmonization would imply lower rents for $A$ than without tax harmonization prompts us to ask whether there is any degree of tax harmonization, any value of $\varepsilon \in\left(0, k\left(x_{B}{ }^{\theta}-x_{A}{ }^{\theta}\right) /(3(1+\alpha))\right)$, that would make higher rents for both countries $A$ and $B$ than without tax harmonization; recall that this is a necessary condition for coordination. Using $x_{A}^{h}=x_{A}^{*}=0, x_{B}^{h}=x_{B}^{*}=\left(\frac{4}{9} \theta k\right)^{\frac{1}{1-\theta}}, \tau_{A}^{h}=\tau_{A}^{*}+\varepsilon=\frac{1}{3} k\left(x_{B}^{h}\right)^{\theta}+\varepsilon$ and $\tau_{B}^{\mu}=\frac{2}{3} k\left(x_{B}^{h}\right)^{\theta}-\alpha \varepsilon$ in the expressions for $\hat{s}, r_{A}$, and $r_{B}$, (that is 2.2, 4.2 and 4.3), we obtain the following reduced form expressions for government rents, which under harmonization 
are denoted $r_{A}^{h}(\varepsilon)$ and $r_{B}^{h}(\varepsilon)$ respectively:

$$
\begin{aligned}
& r_{A}^{h}(\varepsilon)=\frac{k}{9}\left(\frac{4}{9} \theta k\right)^{\frac{\theta}{1-\theta}}-\frac{1}{3}\left(\alpha+\frac{3(1+\alpha)}{k\left(\frac{4}{9} \theta k\right)^{\frac{\theta}{1-\theta}}} \varepsilon\right) \varepsilon \\
& r_{B}^{h}(\varepsilon)=\left(\frac{1}{\theta}-1\right)\left(\frac{4}{9} \theta k\right)^{\frac{1}{1-\theta}}+\frac{2}{3} \varepsilon-\frac{\alpha(1+\alpha)}{\left(\frac{4}{9} \theta k\right)^{\frac{\theta}{1-\theta}}} \varepsilon^{2} .
\end{aligned}
$$

By inspection, $r_{A}^{h}(\varepsilon)$ is monotonically decreasing in $\varepsilon$ for all possible values of $\alpha$ while $r_{B}^{h}(\varepsilon)$ is concave in $\varepsilon$ if $\alpha$ is small but everywhere decreasing in $\varepsilon$ for $\alpha$ sufficiently large.

We can therefore see without further analysis that $A$ would only choose $\varepsilon=0$; it would not agree to any degree of tax harmonization. This is true even if $\alpha=0$; Country $B$ would only be constrained by tax harmonization to the extent that it cannot raise its tax above $\tau_{B}^{*}$. As well as telling us that $A$ will not agree to tax harmonization, this also helps us to understand why a minimum tax is workable; it is because Country $B$ is able to bestrespond by raising its tax, hence making itself less attractive to firms at the bottom of the distribution, that enables Country $A$ in turn to retain a relatively large share of firms. Hence, by imposing higher taxes on this relatively large share of firms, $A$ 's rents increase under a minimum tax relative to the outcome with no tax policy coordination, in contrast to the outcome under any degree of tax harmonization.

Overall, then, tax harmonization appears to have more favorable efficiency implications than a minimum tax but its distributional properties appear to limit its applicability. Government $B$ makes higher rents than without harmonization for $\alpha \leq 1$, although there exist values of $\alpha$ high enough that $B$ would lose from tax harmonization as well. In this situation the gains from tax harmonization would be transferred from governments to firms. If $B$ were to gain under tax harmonization then this would essentially be because more firms would locate in $B$. In general there would be an increase in firm profits because more firms would locate in $B$ and taxes would be lower there than without tax harmonization. The distributive effects are unfavorable to $A$ though, and this seems likely to prevent the implementation of tax harmonization unless side-payments were introduced to compensate. ${ }^{34}$

\footnotetext{
${ }^{34}$ The logic of this analysis also applies in the model with congestion costs.
} 


\section{Relation to the Literature and Conclusions}

It was mentioned in the introduction that the tax competition literature focuses on three different situations. We will now consider the literature in each of these areas in turn and how the present paper relates to it. Before focusing on specific areas of the literature it is worth briefly noting that in this present paper each government presides over a country whereas in much of the tax competition literature governments preside over jurisdictions more broadly defined. ${ }^{35}$

The first area of focus is where there is a fiscal externality created by the fact that governments must rely on taxation of mobile capital while labor (also referred to as residents) is immobile. This is sometimes referred to as 'basic' or 'standard' tax competition. Asymmetric equilibria have been studied before in such tax competition models; see for example Wilson $(1987,1991)$. In Wilson (1991), one country is larger in the sense that it is endowed with more labor (the immobile factor). Then the larger country sets its tax rate closer to (but still below) the social optimum, and higher than the smaller country, but at the cost of allowing some of its (also larger) capital endowment to move to the other country. ${ }^{36}$ The asymmetry of tax levels across countries results from the assumed asymmetry of endowments while in our work, in equilibrium, the asymmetry of country size and the difference in tax levels across countries are co-determined.

It has been argued in prior literature, in a 'standard tax competition' setting where tax competition is harmful, that the primary purpose of a minimum tax is to limit socially wasteful competition between the governments. This is the spirit in which a minimum tax is applied in Keen and Marchand (1997), for example. In our framework, a minimum tax acts in a similar spirit to reduce waste. But it works in a different way, by increasing the

\footnotetext{
${ }^{35}$ Thus, while the issues that we investigate are similar to the problems of fiscal federalism investigated by Arnott and Grieson (1981), Gordon (1983) and Wilson (1986), the range of policy options that we consider are more limited than under federalism, mirroring more closely an international setting. Other papers placed in an international setting include Wilson $(1987,1991)$, Kanbur and Keen (1993) and Baldwin and Krugman (2004).

${ }^{36}$ Wilson (1987) studies a model of Heckscher-Ohlin trade and tax competition, where one country is endowed with more capital than the other. Consequently, public good provision is above the efficient level in one country and inefficiently low in the other.
} 
intensity of tax competition. ${ }^{37}$

The second situation analyzed in the literature on tax competition is where competition promotes efficiency. Tiebout (1956) was the first to discuss the idea that competition between jurisdictions may promote efficiency if citizens are able to sort themselves into jurisdictions composed of those with similar preferences for public good provision and hence a similar willingness to pay. Brueckner (2000) sets up a framework for the consideration of Tiebout issues (differences in tastes for public services) and tax competition within a unified framework. The model of the present paper shares the feature of Tiebout-tax competition that there is variation in firms' public good requirements. Another common feature is that governments' objectives are entirely self-serving in that they are profit/rent maximizing but are constrained by competition. However, following the structure of Kanbur and Keen's (1993) tax competition model, in our model a firm cannot be disaggregated into its capital and labor inputs. Consequently, the results of the present paper contrast with those of the Tiebout-tax competition literature in that more capital (i.e. a bigger share of firms) locates in the country with higher taxation.

Since there is no policy-failure in the Tiebout-tax competition model, efficiency is achieved in equilibrium through the entry of many jurisdictions. ${ }^{38}$ In our model, by contrast, there is 'policy-failure' in the sense that once levels of public goods are fixed they cannot be altered. This notionally creates barriers to entry of new countries, enabling existing countries to make positive rents. Since the present paper is placed in an international setting, it seems reasonable to take the number of countries as given. Alternatively, seeking parallels with the literature on Tiebout-tax competition, the 'entry' of new countries could be studied in our framework as well. The underlying structure of our model is developed in an industrial-organization setting by Shaked and Sutton (1982) and Sutton (1991 Chapter

\footnotetext{
${ }^{37}$ Keen and Marchand (1997) show that raising the minimum tax also increases efficiency due to the effect on the composition of public spending. Questions concerning the composition of spending are beyond the scope of the present paper.

${ }^{38}$ Other voting or bidding mechanisms have been shown to achieve efficiency in tax competition. Oates and Schwab (1988) show that majority rule can select the efficient outcome when there is interjurisdictional competition for mobile resources. Black and Hoyt (1989) show how the process by which jurisdictions bid for firms may promote efficiency. The promotion of efficiency within the context of competition has also been discussed by Boadway, Cuff and Marceau (2002), Boadway, Pestieau and Wildasin (1989) among others. Lockwood and Makris (2006) show that wasteful tax competition can be offset through the political process.
} 
3) in models of vertical product competition between firms. Allowing free entry to occur in principle, Shaked and Sutton show conditions under which only two firms survive in equilibrium. Future work might identify such conditions in our tax-competition framework as well. ${ }^{39}$

Casella and Feinstein (2002) describe the same variation in public good requirements that we have in mind: "[Public goods] can be given a physical interpretation - roads, airports, infrastructure - or ... they can be more abstract - laws and legal enforcement, rules and conventions, standards and regulations, currency and language. The key feature is that preferences over the specific realization of the public good are not homogeneous among all market participants, but depend on the individual's position within the market." For example, in the textiles and apparel market, at the 'top' of the market there is 'haute couture,' consisting of the leading innovators in the industry. These firms make extensive use of international travel and communications networks, employ highly educated and trained workers, and rely on intellectual property laws to safeguard returns on the designs that they produce. At the 'bottom' end of the market there are so-called 'sweat shops' that employ local and relatively low skilled workers, source inputs locally, and tend to copy rather than create the designs that they use, and therefore do not rely on intellectual property protection. ${ }^{40}$

A related idea to ours is explored by Hoyt and Jensen (2001). They too borrow the idea from the literature on vertical product differentiation and apply the analogy to the level of public good provision within the context of tax competition. However, their main focus is on the capitalization into house prices of the quality of public school provision. While tax competition is a feature of their model, they do not develop the idea of intense international tax competition as we do here. And their setting is essentially within the nation so issues of

\footnotetext{
${ }^{39}$ In the sense of Sutton (1991 Chapter 3), one might say that we have a model of vertical public good differentiation, in which expenditure on public goods may be thought of as a sunk cost. This is not to be confused with vertical tax competition discussed by Dahlby and Wilson (2003) or Keen and Kotsogiannis (2003), for example, which relates to competition between governments at the 'federal' and 'state' levels. Wilson and Janeba (2005) show that a country's decentralization level serves as a strategic tool under tax competition which may improve welfare. See also Devereux, Lockwood and Redoano (2006), who consider the interaction of horizontal and vertical tax competition.

${ }^{40}$ Casella and Feinstein (2002) do not focus on tax competition. Our notion of public good is consistent with other terms used in the literature, including public service (Black and Hoyt 1989), public infrastructure (Justman, Thisse and van Ypersele 2002) and public input (Bucovetsky 2005).
} 
tax coordination are not discussed.

Justman, Thisse and van Ypersele (2002) also study a related idea that under fiscal competition regions can segment the market for industrial location by offering infrastructure services that are differentiated by quality. They identify a fiscal agglomeration property, which motivates an asymmetric equilibrium in which one jurisdiction offers a subsidy but offers public goods at a low level while another jurisdiction offers a higher level of public good provision but charges a positive 'entry fee' to the jurisdiction. However, they do not consider tax competition nor cooperation over taxes, and do not compare their equilibrium outcome to efficiency. Hence they do not characterize the relationship between the effectiveness at reducing costs of public good provision and the degree to which the intensity of tax competition is reduced. ${ }^{41}$

Some models of tax competition obtain asymmetry of outcomes as a consequence of increasing returns to scale. In that setting, industrial concentration creates 'agglomeration rent' (Baldwin and Krugman 2004). Firms benefit from the externalities of location and the government is able to extract some of this surplus through higher taxation. These externalities play essentially the same role as the public good externalities in the model of this present paper (see also Kind, Knarvik and Schelderup 2000 and Ludema and Wooton 2000). Since agglomoration externalities and public good externalities play similar roles in the models, it is not surprising that policies of tax coordination have similar effects as well. Baldwin and Krugman show, in keeping with our results, that tax harmonization may make one or both nations worse off while a minimum tax (which they refer to as 'tax-floor harmonization') may benefit both countries.

Since our model exhibits the feature that one country sets a higher tax rate than the other, it presents an alternative explanation for the sustained difference in tax rates across countries. ${ }^{42}$ While the literature on international tax competition has focused mainly on the fall in tax rates on capital across countries, attention has recently been drawn to the fact

\footnotetext{
${ }^{41} \mathrm{~A}$ framework of horizontal (as opposed to vertical) product differentiation has also been adapted in previous work to the context of tax competition; see Justman, Thisse and van Ypersele (2005) for a recent contribution and review of the literature; see also Groenert, Wooders and Zissimos (2006).

${ }^{42}$ This feature is of course shared by all of the other models referred to above that exhibit asymmetric equilibria.
} 
that some countries have continued to tax at higher rates than others. For example, Baldwin and Krugman (2004) comment with reference to European nations that it has always been the case that tax rates have been higher in the core than the periphery. ${ }^{43}$ Acknowledging the crudeness of the approximation, Baldwin and Krugman present data to show that capital tax rates in the 'core' countries France, Germany, Italy and Benelux have always been higher than tax rates in the poorer periphery countries Ireland, Greece, Portugal and Spain. In 1982 the effective average tax rate (EATR) in the core was 42 percent compared to 31 percent in the periphery, while in 2003 the EATR in the core was 31 percent compared to 23 percent in the periphery. These figures support the general observation that, while tax rates have fallen between 1982 and 2003, convergence between the core and periphery rates has been limited. ${ }^{44}$

Although our model can explain in static terms why taxes and public good provision may be higher in one country than another, it is silent on the dynamics of how taxes have evolved over time. While some commentators have taken evidence of falling taxes across all countries to suggest that tax rates will eventually converge, our model suggests that the long run equilibrium will exhibit differentiation in tax levels across countries. An agenda for future research is to explain how average tax rates fall over time as markets become more integrated while still maintaining a stable differential between the core and the periphery.

While we relate the predictions of our model to patterns of international capital taxation, a looser interpretation could be extended to explain the pattern of taxation across states in a federation. For example, the variation in tax rates across states in the US has attracted significant media attention, with the spotlight focused on discrepancies between states where taxes and public good provision are relatively high, like Massachusetts, and those where taxes and public good provision are at low levels, such as Alabama. Our model, while

\footnotetext{
${ }^{43}$ Tax rates and incomes in some countries traditionally regarded to be on the periphery of Europe have risen recently (Baldwin and Krugman 2004), leading to suggestions that traditional 'core-periphery' distinctions may no longer be valid. We would argue, as do Baldwin and Krugman, that overall the distinction is still valid, and that it is being reinforced by the arrival of new countries on the 'periphery.' These countries have capital tax rates that are significantly lower than the core and this has prompted new concerns about the differences in tax levels and new questions about appropriate policy responses (EUbusiness 2004). Of course, there are undoubtedly features beyond the scope of our model which play an additional role in shaping core-periphery relationships.

${ }^{44}$ These averages are calculated from data provided by Devereux and Griffith (2003), and made available at http://www.ifs.org.uk/corptax/internationaltaxdata.zip. These data focus specifically on taxation of capital.
} 
focused on international taxation, puts forward a way of understanding these patterns of variation in taxation across states as well, characterizing a situation where federal transfers between states are imperfect. Future research could usefully extend our work to a model of a federation in which a wider range of policy instruments were available.

\section{A. Appendix}

\section{A.1. Proof of Propositions}

Proof of Proposition 1. Without loss of generality, assume that $x_{A} \leq x_{B}$. The planner's problem may be represented as the following constrained optimization problem:

$$
\begin{aligned}
\max _{x_{A}, x_{B}, \hat{s}} \Omega\left(x_{A}, x_{B}, \hat{s}\right) & =(p-c)-x_{A}-x_{B}+\frac{k}{2}\left(x_{B}^{\theta}-\hat{s}^{2}\left(x_{B}^{\theta}-x_{A}^{\theta}\right)\right), \\
\text { s.t. } x_{A} & \geq 0, x_{B} \geq 0, \hat{s} \in[0,1] .
\end{aligned}
$$

This problem can be solved using the Kuhn-Tucker conditions providing that $\Omega\left(x_{A}, x_{B}, \hat{s}\right)$ is quasi-concave in its arguments (it is immediate that the constraint $\hat{s} \in[0,1]$ is convex). But note that a unique solution may be obtained directly from the first order conditions for the arguments $x_{A}, x_{B}$, and $\hat{s}$ :

$$
x_{A}^{E}=\left(\frac{\hat{s} \theta k}{2}\right)^{\frac{1}{1-\theta}} ; x_{B}^{E}=\left(\frac{(1-\hat{s}) \theta k}{2}\right)^{\frac{1}{1-\theta}} ; \hat{s}^{E}=0 .
$$

Using the fact that $\hat{s}=0$ in the other two conditions, we obtain the efficient public good levels, namely $x_{A}^{E}=0, x_{B}^{E}=\left(\frac{\theta k}{2}\right)^{\frac{1}{1-\theta}}$. The constraints are not strictly binding and are not needed to obtain the solution. To confirm quasi-concavity of $\Omega\left(x_{A}, x_{B}, \hat{s}\right)$, show that the second order condition for a maximum holds at any critical point. That is, substitute the solution values $x_{A}^{E}=0, x_{B}^{E}=\left(\frac{\theta k}{2}\right)^{\frac{1}{1-\theta}}$ and $\hat{s}=0$ into the first, second and third principal minors of the Hessian formed by $\Omega\left(x_{A}, x_{B}, \hat{s}\right)$, thus confirming that the signs alternate appropriately for the matrix to be negative semi-definite as required.

Proof of Lemma 1. Fix $0 \leq x_{A}<x_{B}$ and fix $\tau_{B}$. Government $A$ 's best response tax function $T_{A}\left(\tau_{B}\right)$ is given by the solution to the problem

$$
\max _{\tau_{A}} r_{A}\left(\tau_{A}, \tau_{B}\right)=\frac{\tau_{A}\left(\tau_{B}-\tau_{A}\right)}{k\left(x_{B}^{\theta}-x_{A}^{\theta}\right)}-x_{A} .
$$


First, looking at the second order condition, we see that

$$
d^{2} r_{A} / d \tau_{A}^{2}=-2 /\left(k\left(x_{B}{ }^{\theta}-x_{A}{ }^{\theta}\right)\right)<0,
$$

so $r_{A}\left(\tau_{A}, \tau_{B}\right)$ is everywhere concave with respect to $\tau_{A}$. Setting the first order condition $d r_{A} / d \tau_{A}=\left(-2 \tau_{A}^{*}+\tau_{B}\right) /\left(k\left(x_{B}^{\theta}-x_{A}^{\theta}\right)\right)$ equal to zero and rearranging in terms of $\tau_{A}^{*}$ obtains $T_{A}\left(\tau_{B}\right)=\tau_{B} / 2$.

Now fix $\tau_{A}$. Government $B$ 's best response tax function $T_{A}\left(\tau_{B}\right)$ is given by the solution to the problem

$$
\max _{\tau_{B}} r_{B}\left(\tau_{A}, \tau_{B}\right)=\tau_{B}\left(1-\frac{\left(\tau_{B}-\tau_{A}\right)}{k\left(x_{B}^{\theta}-x_{A}{ }^{\theta}\right)}\right)-x_{B} .
$$

Again, looking at the second order condition first, we see that

$$
d^{2} r_{B} / d \tau_{B}^{2}=-2 /\left(k\left(x_{B}^{\theta}-x_{A}^{\theta}\right)\right)<0,
$$

so $r_{B}\left(\tau_{A}, \tau_{B}\right)$ is concave with respect to $\tau_{B}$. Setting the first order condition $d r_{B} / d \tau_{B}=$ $1+\left(\tau_{A}-2 \tau_{B}^{*}\right) /\left(k\left(x_{B}{ }^{\theta}-x_{A}{ }^{\theta}\right)\right)$ equal to zero and rearranging in terms of $\tau_{B}$ obtains the result.

Proof of Proposition 2. By assumption, if $x_{A}=x_{B} \geq 0$ or $k=0$ then we have Bertrand competition, so $\tau_{A}^{*}=\tau_{B}^{*}=0$ and $\hat{s}=1 / 2$. Mutual best-responses are obtained by solving simultaneously for $\tau_{A}^{*}$ and $\tau_{B}^{*}$ using the best-response tax functions: $\tau_{A}^{*}=\tau_{B}^{*} / 2 ; \tau_{B}^{*}=\tau_{A}^{*} / 2+$ $k\left(x_{B}{ }^{\theta}-x_{A}{ }^{\theta}\right) / 2$. Using the results, $\tau_{A}^{*}\left(x_{A}, x_{B} ; k\right)=k\left(x_{B}{ }^{\theta}-x_{A}{ }^{\theta}\right) / 3$ and $\tau_{B}^{*}\left(x_{A}, x_{B} ; k\right)=$ $2 k\left(x_{B}^{\theta}-x_{A}^{\theta}\right) / 3$, in $\hat{s}=\left(\tau_{B}-\tau_{A}\right) / k\left(x_{B}^{\theta}-x_{A}^{\theta}\right)$ obtains $\hat{s}=1 / 3$.

Proof of Proposition 3: To determine Government $A$ 's set of best responses, we investigate the properties of $r_{A}\left(x_{A}, x_{B}\right)$. It is clear by inspection of (4.2) that $r_{A}\left(x_{A}, x_{B}\right)$ achieves a minimum at $x_{A}=x_{B}$. So we can rule out $x_{A}=x_{B}$ from $B R_{A}\left(x_{B}\right)$. Now observe that if $0 \leq x_{A}<x_{B}$ then $r_{A}=k\left(x_{B}{ }^{\theta}-x_{A}{ }^{\theta}\right) / 9-x_{A}$ so $r_{A}\left(x_{A}, x_{B}\right)$ is everywhere downward sloping and convex over this range. Consequently, $x_{A}=0$ maximizes $r_{A}\left(x_{A}, x_{B}\right)$ for $0 \leq$ $x_{A}<x_{B}$. If on the other hand $0 \leq x_{B}<x_{A}$, then $r_{A}=4 k\left(x_{A}{ }^{\theta}-x_{B}{ }^{\theta}\right) / 9-x_{A}$, and $r_{A}\left(x_{A}, x_{B}\right)$ is everywhere strictly concave. Differentiating once, setting the result equal to zero and rearranging, we find that $r_{A}\left(x_{A}, x_{B}\right)$ has a unique maximum at $x_{A}=\left(\frac{4}{9} \theta k\right)^{\frac{1}{1-\theta}}$. Thus $B R_{A}\left(x_{B}\right) \in\left\{0,\left(\frac{4}{9} \theta k\right)^{\frac{1}{1-\theta}}\right\}$. Because $r_{B}\left(x_{A}, x_{B}\right)$ has the same functional form as $r_{A}\left(x_{A}, x_{B}\right)$, it follows that $B R_{B}\left(x_{A}\right) \in\left\{0,\left(\frac{4}{9} \theta k\right)^{\frac{1}{1-\theta}}\right\}$; see (4.3). Recall that $r_{A}\left(x_{A}, x_{B}\right)$ and 
$r_{B}\left(x_{A}, x_{B}\right)$ achieve a minimum at $x_{A}=x_{B}$. So $\left\{0,\left(\frac{4}{9} \theta k\right)^{\frac{1}{1-\theta}}\right\}$ is the only set of mutual best responses and must therefore be a Nash equilibrium. Clearly, there are two Nash equilibria; $\left\{0,\left(\frac{4}{9} \theta k\right)^{\frac{1}{1-\theta}}\right\}$ and $\left\{\left(\frac{4}{9} \theta k\right)^{\frac{1}{1-\theta}}, 0\right\}$. But we may now assume, without loss of generality, that $x_{A}<x_{B}$. Then $\left(x_{A}^{*}, x_{B}^{*}\right)=\left\{0,\left(\frac{4}{9} \theta k\right)^{\frac{1}{1-\theta}}\right\}$ is the unique Nash equilibrium. Using these values to solve for equilibrium taxes from Proposition 2, we have that $\tau_{A}^{*}=\frac{1}{3} k\left(\frac{4}{9} \theta k\right)^{\frac{\theta}{1-\theta}}$ and $\tau_{B}^{*}=\frac{2}{3} k\left(\frac{4}{9} \theta k\right)^{\frac{\theta}{1-\theta}}$. Thus we have the result.

Proof of Proposition 4. First note that $r_{B}^{\mu}(\varepsilon)$ increases monotonically with $\varepsilon$. On the other hand, $r_{A}^{\mu}(\varepsilon)$ is concave in $\varepsilon$; to see this, differentiate $r_{A}^{\mu}(\varepsilon)$ once with respect to $\varepsilon$ to obtain

$$
\frac{d r_{A}^{\mu}(\varepsilon)}{d \varepsilon}=\frac{1}{6}-\frac{\varepsilon}{k\left(\left(\frac{4}{9} \theta k\right)^{\frac{\theta}{1-\theta}}\right)} .
$$

Clearly, $d r_{A}^{\mu}(\varepsilon) / d \varepsilon>0$ as $\varepsilon \rightarrow 0$ and $d r_{A}^{\mu}(\varepsilon) / d \varepsilon<0$ as $\varepsilon$ becomes large. Also, $d r_{A}^{\mu}(\varepsilon) / d \varepsilon$ declines monotonically with $\varepsilon$. The unique value of $\varepsilon$ that maximizes $r_{A}^{\mu}$ is $\varepsilon=\frac{1}{6} k\left(\frac{4}{9} \theta k\right)^{\frac{\theta}{1-\theta}}$. By definition, a minimum tax for which $\varepsilon<\frac{1}{6} k\left(\frac{4}{9} \theta k\right)^{\frac{\theta}{1-\theta}}$ cannot be on the frontier because both governments make higher rents by increasing $\varepsilon$ to $\varepsilon=\frac{1}{6} k\left(\frac{4}{9} \theta k\right)^{\frac{\theta}{1-\theta}}$; thus we have defined the lower bound of the non-renegotiable minimum-tax-frontier.

By definition, the minimum tax on the frontier must yield higher rents for both governments than no minimum tax. Because $r_{B}^{\mu}(\varepsilon)$ increases monotonically with $\varepsilon, B$ makes higher rent with any minimum tax than with no minimum tax. However, $r_{A}^{\mu}(\varepsilon)$ declines monotonically with $\varepsilon$ for $\varepsilon>\frac{1}{6} k\left(\frac{4}{9} \theta k\right)^{\frac{\theta}{1-\theta}}$. Therefore, a level of $\varepsilon>\frac{1}{6} k\left(\frac{4}{9} \theta k\right)^{\frac{\theta}{1-\theta}}$ must exist at which $r_{A}^{\mu}(\varepsilon)=r_{A}^{\mu}(0)$. It is easy to establish that $r_{A}^{\mu}(0)=\frac{2}{3} k\left(\frac{4}{9} \theta k\right)^{\frac{\theta}{1-\theta}}$. Then $\varepsilon=\frac{1}{3} k\left(\frac{4}{9} \theta k\right)^{\frac{\theta}{1-\theta}}$ is the unique level of $\varepsilon>\frac{1}{6} k\left(\frac{4}{9} \theta k\right)^{\frac{\theta}{1-\theta}}$ at which $r_{A}^{\mu}(\varepsilon)=r_{A}^{\mu}(0)$; thus we have defined the upper bound of the non-renegotiable minimum-tax-frontier.

\section{A.2. The Model with Congestion Costs}

Congestion costs can be introduced in a simple way, following Ahlin and Ahlin (2006). Define as $\hat{s}_{c}$ the firm that is just indifferent between locating in either country when congestion has a negative impact on profits. Specifically, we will say that if firm $s \in[0,1]$ locates in Country $A$ then its profits are reduced in proportion to the overall share of firms that locate in $A$, $\phi \hat{s}_{c}$, where $\phi \geq 0$ is a parameter. Similarly, if $s$ locates in Country $B$ then its profits are 
reduced by $\phi\left(1-\hat{s}_{c}\right)$. Otherwise, the model of firms is the same as specified in Section 2 . Now, the profit function for the firm at $s \in[0,1]$ is given by

$$
\pi_{s}=\left\{\begin{array}{cl}
p-c-\tau_{A}+s k x_{A}{ }^{\theta}-\phi \hat{s}_{c} & \text { if } s \text { locates in } A \\
p-c-\tau_{B}+s k x_{B}^{\theta}-\phi\left(1-\hat{s}_{c}\right) & \text { if } s \text { locates in } B
\end{array} .\right.
$$

Then

$$
\tau_{A}-\hat{s}_{c} k x_{A}^{\theta}-\phi \hat{s}_{c}=\tau_{B}-\hat{s}_{c} k x_{B}^{\theta}-\phi\left(1-\hat{s}_{c}\right) \text {. }
$$

Solve the above expression for $\hat{s}_{c}$ and hence define the function

$$
\hat{s}_{c}\left(\tau_{A}, \tau_{B}, x_{A}, x_{B} ; \phi\right)=\frac{\tau_{B}-\tau_{A}+\phi}{k\left(x_{B}{ }^{\theta}-x_{A}{ }^{\theta}\right)+2 \phi}
$$

Then $\hat{s}_{c}$ is defined as follows:

$$
\hat{s}_{c}=\left\{\begin{array}{c}
\hat{s}_{c}\left(\tau_{A}, \tau_{B}, x_{A}, x_{B} ; \phi\right) \text { if } \hat{s}_{c}\left(\tau_{A}, \tau_{B}, x_{A}, x_{B} ; \phi\right) \in[0,1] \\
1 \text { if } \hat{s}_{c}\left(\tau_{A}, \tau_{B}, x_{A}, x_{B} ; \phi\right)>1 \\
0 \text { if } \hat{s}_{c}\left(\tau_{A}, \tau_{B}, x_{A}, x_{B} ; \phi\right)<0
\end{array}\right.
$$

For $x_{A}=x_{B}$

$$
\hat{s}_{c}=\left\{\begin{array}{l}
0 \text { if } \tau_{A}<\tau_{B} \\
1 \text { if } \tau_{A}>\tau_{B} \\
\frac{1}{2} \text { if } \tau_{A}=\tau_{B}
\end{array}\right.
$$

The rents to office functions for Governments $A$ and $B$ remain as $r_{A}=\tau_{A} \hat{s}-x_{A}$ and $r_{B}=\tau_{B}(1-\hat{s})-x_{B}$ respectively.

First, let us consider the efficient solution with the congestion cost. The congestion cost enters the expression for efficiency through firms' profits, so that the planner's problem (3.1) becomes

$$
\max _{x_{A}, x_{B}, \hat{s}_{c}} \Omega\left(x_{A}, x_{B}, \hat{s}_{c}\right)=p-c-x_{A}-x_{B}+\frac{k}{2}\left(x_{B}^{\theta}-\hat{s}_{c}^{2}\left(x_{B}^{\theta}-x_{A}^{\theta}\right)\right)-2\left(1-\hat{s}_{c}+\hat{s}_{c}^{2}\right) \phi .
$$

A solution may be obtained once again from the first order conditions for $x_{A}, x_{B}$ and $\hat{s}$ :

$$
x_{A}^{E}=\left(\frac{\hat{s} \theta k}{2}\right)^{\frac{1}{1-\theta}} ; x_{B}^{E}=\left(\frac{(1-\hat{s}) \theta k}{2}\right)^{\frac{1}{1-\theta}} ; \hat{s}_{c}^{E}=\frac{2 \phi}{k\left(x_{B}^{\theta}-x_{A}^{\theta}\right)+4 \phi} .
$$

Note that while the solutions for $x_{A}^{E}$ and $x_{B}^{E}$ are exactly as in the case with no congestion costs, we have $\hat{s}_{c}^{E}>0$ if $\phi>0$ (and $x_{B}>x_{A} \geq 0$ ). Thus, as one should expect, in the presence of the congestion cost it is no longer efficient for the planner to induce all firms to locate in the same country. 
The next step would be to obtain reduced form solutions by, for example, substituting the solution for $\hat{s}_{c}^{E}$ into $x_{A}^{E}$ and $x_{B}^{E}$. Attempting to do so reveals that it is not possible to solve for general closed form solutions, although it is possible to get some indication of what a general solution might look like by solving for specific values of $\theta$ such as $\theta=\frac{1}{2}$.

We are nevertheless able to address our main concern regarding congestion costs using the above solutions, which is whether and to what extent their presence offsets the effects of public good differentiation on tax competition. This is done by obtaining a value for $\hat{s}_{c}^{E}$ when congestion costs are as large as possible. Observe that $\hat{s}_{c}^{E} \rightarrow \frac{1}{2}$ (from below) as $\phi \rightarrow \infty$. As an approximation, use the value $\hat{s}_{c}^{E}=\frac{1}{2}$ in the above solutions for $x_{A}^{E}$ and $x_{B}^{E}$ to obtain closed form solutions:

$$
x_{A}^{E}=\left(\frac{\theta k}{8}\right)^{\frac{1}{1-\theta}}, x_{B}^{E}=\left(\frac{3 \theta k}{8}\right)^{\frac{1}{1-\theta}} .
$$

From these solutions we see that countries tend to be of more similar size when congestion costs are large, and the difference between the levels of public good provision is reduced. Country A does provide a positive amount of the public good and Country B proves less then than when congestion costs are absent. However, in spite of the fact that the public good eliminates the difference in the size of the countries, the difference in the efficient level of public good provision is not eliminated, with $x_{B}^{E}>x_{A}^{E}$ for all $k>0$ and $\theta \in(0,1)$, and $x_{B}^{E} / x_{A}^{E}$ increases in $\theta$ and $k$. Concavity of $\Omega\left(x_{A}, x_{B}, \hat{s}_{c}\right)$ can be verified for the case where $\hat{s}_{c}$ in the usual way.

Let us now solve for the tax subgame in the presence of the congestion cost. Solving as in Section 4.1, we obtain the following. For $x_{A}=x_{B}$, both governments provide the same level of public good and there exists a unique equilibrium in which $\tau_{A}^{*}=\tau_{B}^{*}=\phi$. For $x_{A} \neq x_{B}$ we assume as usual that $x_{A}<x_{B}$. Then there exists a unique subgame equilibrium point determined by the taxes

$$
\begin{aligned}
\tau_{A}^{*}\left(x_{A}, x_{B}\right) & =\frac{1}{3} k\left(x_{B}{ }^{\theta}-x_{A}{ }^{\theta}\right)+\phi ; \\
\tau_{B}^{*}\left(x_{A}, x_{B}\right) & =\frac{2}{3} k\left(x_{B}{ }^{\theta}-x_{A}{ }^{\theta}\right)+\phi .
\end{aligned}
$$

As for the case with no congestion costs the difference between tax $\tau_{A}^{*}\left(x_{A}, x_{B}\right)$ and $\tau_{B}^{*}\left(x_{A}, x_{B}\right)$ is proportional to the difference between $x_{B}$ and $x_{A}$, and the size of $k ; \tau_{B}^{*}-\tau_{A}^{*}=k\left(x_{B}{ }^{\theta}-x_{A}{ }^{\theta}\right) / 3$. And the equilibrium tax levels $\tau_{A}^{*}$ and $\tau_{B}^{*}$ increase as either $x_{B}{ }^{\theta}-x_{A}{ }^{\theta}$ or $k$ is increased. At 
$\tau_{A}^{*}\left(x_{A}, x_{B} ; k\right)$ and $\tau_{B}^{*}\left(x_{A}, x_{B} ; k\right)$, the share of firms locating in Country $A$ is given by

$$
\hat{s}_{c}=\frac{1}{3}\left(1+\frac{\phi}{k\left(x_{B}^{\theta}-x_{A}^{\theta}\right)+2 \phi}\right) .
$$

As with the efficient solution, the congestion costs act to push firms towards Country $A$. If $\phi=0$ then $\hat{s}_{c}=1 / 3$ as we should expect. And $\hat{s}_{c}$ is increasing in $\phi$. Also, as we shall see, $x_{B}$ is decreasing in $\phi$ (both in absolute terms and relative to $x_{A}$ ) the effect of which contributes further to an increase in $\hat{s}_{c}$. Note also that $\hat{s}_{c}$ is bounded from above at $\frac{1}{2}$.

Finally, we can now solve for the equilibrium level of public good provision in Stage 1. With congestion costs, the first order condition for the maximization of rents in Country $A$ becomes

$$
\frac{d r_{A}}{d x_{A}}=-1+\frac{1}{9} \theta k x_{A}^{\theta-1}\left(-1+\frac{\phi^{2}}{\left(k\left(x_{B}^{\theta}-x_{A}^{\theta}\right)+2 \phi\right)^{2}}\right)
$$

It is straight-forward to verify that $d r_{A} / d x_{A}<0$. This is immediate when $\phi=0$. Now observe that the second term in the interior brackets on the right hand side converges to $1 / 4$ as $\phi$ becomes large. So the sum of the terms in the brackets must always be negative. Therefore, $x_{A}^{*}=0$ in equilibrium, as with no congestion costs (Proposition 3 ).

Also,

$$
\frac{d r_{B}}{d x_{B}}=-1+\frac{1}{9} k \theta x_{B}^{\theta-1}\left(4-\frac{\phi^{2}}{\left(k\left(x_{B}^{\theta}-x_{A}^{\theta}\right)+2 \phi\right)^{2}}\right)
$$

The second term in brackets determines the impact of the congestion cost on $x_{B}^{*}$. We can see by inspection that $x_{B}^{*}$ is positive and decreasing in the size of $\phi$ (equal to the value in Proposition 3 for $\phi=0)$.

The negative impact of $\phi$ is larger in $d \Omega / d x_{B}$ (not shown) than in $d r_{B} / d x_{B}$. That is, the (negative) term in $\phi$ in the brackets is bigger in $d \Omega / d x_{B}$ than in $d r_{B} / d x_{B}$. This implies that for large $\phi$ there is over-provision of the public good in Country $\mathrm{B} ; x_{B}^{*}>x_{B}^{E}$. Solving for $x_{B}^{*}$ as $\phi$ becomes large, we obtain $x_{B}^{*}=\left(\frac{15}{16} \theta k\right)^{\frac{1}{1-\theta}}>x_{B}^{E}=\left(\frac{3}{8} \theta k\right)^{\frac{1}{1-\theta}}$. This stands to reason. As remarked above, the congestion cost induces more firms to locate in Country $A$. In equilibrium taxes are equalized whether congestion costs are present or not. Country $B$ tries to offset the loss of firms, and hence rents, by providing the public good at a higher level. In addition note that $x_{A}^{E}>x_{A}^{*}=0$ for all $\phi$. So it cannot be said that congestion costs neutralize the effect of reducing the intensity of tax competition. 


\section{A.3. The Role of $\theta$ in the Model}

This discussion continues from the discussion of the effect of $k$ on $x_{B}^{*}$ in Section 4.2. The effect of $\theta$ on $x_{B}^{*}$ is less obvious than the effect on $k$. While for $k$ relatively large, $x_{B}^{*}$ is monotonically increasing in $\theta$, for $k$ relatively small the effect on $x_{B}^{*}$ of an increase in $\theta$ is ambiguous. To show the ambiguity, in Figure 2 we illustrate $r_{B}$ under the assumption that $k=1$ (i.e. relatively small) and that all equilibrium values other than $x_{B}^{*}$ hold; $\tau_{A}=\tau_{A}^{*}$, $\tau_{B}=\tau_{B}^{*}, x_{A}^{*}=0$ and consequently $\hat{s}=\frac{1}{3}$. Using these values, it is easy to work out that $r_{B}=\frac{4}{9} k x_{B}^{\theta}-x_{B}$. Figure 2 illustrates how $r_{B}$ varies with $x_{B}$ for $\theta=\frac{1}{10}, \theta=\frac{1}{4}$ and $\theta=\frac{2}{3}$. We see that for each value of $\theta$ there is a unique value $x_{B}^{*}$ that maximizes $r_{B}$. Moreover, $x_{B}^{*}$ increases as $\theta$ is increased from $\theta=\frac{1}{10}$ to $\theta=\frac{1}{4}$ but $x_{B}^{*}$ decreases as $\theta$ is increased form $\theta=\frac{1}{4}$ to $\theta=\frac{2}{3}$. The reason can be seen most clearly by inspection of the first derivative of the rent function, $d r_{B} / d x_{B}=\frac{4}{9} \theta k x_{B}^{\theta-1}-1$. An increase in $\theta$ has two conflicting effects on the first term. While an increase in $\theta$ tends to increase $\frac{4}{9} \theta k x_{B}$, an increase in $\theta$ tends to decrease $x_{B}^{\theta-1}$ (for fixed $k$ and $x_{B}$ ). Moreover, the negative second effect increases non-linearly with $\theta$. To put this another way, an increase in $\theta$ reduces the curvature of $r_{B}$ everywhere but also reduces the initial gradient of $r_{B}$ in the neighborhood of $x_{B}=0$. Thus $x_{B}^{*}$ may be first increasing then decreasing in $\theta$. However, it is also easy to see that $k$ may be set large enough so that the first term is monotonically increasing in $k$ for $\theta \in(0,1)$. In that case $x_{B}^{*}$ is monotonically increasing in $\theta$ just as it is monotonically increasing in $k$.

The effect of $\theta$ on $x_{B}^{E}$ is very similar, for reasons that are closely related. Observe, by differentiating the planner's problem (3.1), that $d \Omega / d x_{B}=\frac{1}{2} \theta k x_{B}^{\theta-1}-1$. We can see by analogy that, for relatively low $k, x_{B}^{E}$ is first increasing then decreasing in $\theta$. As for $x_{B}^{*}$, it is possible to set $k$ sufficiently large so that $x_{B}^{E}$ is monotonically increasing in $\theta$.

We are also able to see quite clearly the effect of $\theta$ on the suboptimality of public good provision. We do this by calculating the ratio of the level of public good provision at equilibrium and efficient levels in Country $B ; x_{B}^{*} / x_{B}^{E}=\frac{8}{9} \frac{1}{1-\theta}$. Observe that $x_{B}^{*} / x_{B}^{E} \rightarrow \frac{8}{9}$ as $\theta \rightarrow 0$ and $x_{B}^{*} / x_{B}^{E} \rightarrow 0$ as $\theta \rightarrow 1$. We noted above that the effect of an increase in $\theta$ on $x_{B}^{*}$ and $x_{B}^{E}$ may be ambiguous. Recall from Figure 2, for example, that an increase in $\theta$ could bring about an increase in $x_{B}^{*}$ and $x_{B}^{E}$ at $\theta$ relatively close to 0 but a decrease in $x_{B}^{*}$ and $x_{B}^{E}$ at $\theta$ relatively close to 1 . From Proposition 3 it becomes evident that there is a systematic 
effect of $\theta$ on $x_{B}^{*}$ relative to $x_{B}^{E}$ in spite of the ambiguous effect of $\theta$ on the levels of $x_{B}^{*}$ and $x_{B}^{E}$.

\section{References}

[1] Ahlin, C. and P. Ahlin (2006); "Hotelling Was Right about Congestible Goods" Vanderbilt University Typescript.

[2] Arnott, R. and R.E. Grieson (1981); "Optimal Fiscal Policy for a State or Local Government." Journal of Urban Economics, 9: 23-48 (January).

[3] Baldwin, R. and P. Krugman (2004); "Agglomeration, Integration and Tax Harmonization." European Economic Review 48(1): 1-23.

[4] Black, D. and W.H. Hoyt (1989): "Bidding for Firms." American Economic Review, 79(5): 1249-1256.

[5] Bond, E. and T. Gresik (1996); "Regulation of Multinational Firms with Two Active Governments: A Common Agency Approach," Journal of Public Economics, 59(1): 33-53.

[6] Boadway, R., K. Cuff and N. Marceau (2002); "Inter-jurisdictional Competition for Firms," International Economic Review, 43(5): 761-782.

[7] Boadway, R. P. Pestieau and D.E. Wildasin (1989); "Non-cooperative Behavior and Efficient Provision of Public Goods," Public Finance, 44(1): 1-7.

[8] Brennan, G. and J.M. Buchanan, (1980); The Power To Tax: Analytical Foundations of a Fiscal Constitution, Cambridge University Press, Cambridge.

[9] Brueckner, J.K. (2000); “A Tiebout/Tax-Competition Model." Journal of Public Economics, 77: 285-306.

[10] Bucovetsky, S. (2005); "Public Input Competition." Public Input Competition, 89: 1763-1787.

[11] Casella, A. and J.S. Feinstein (2002); "Public Goods in Trade: On the Formation of Markets and countries." International Economic Review 43: 437-462.

[12] Dahlby, B., and L.S. Wilson (2003); "Vertical Fiscal Externalities." Journal of Public Economics, 87: 917-930.

[13] Devereux, M.P. and R. Griffith (2003); "Evaluating Tax Policy for Location Decisions." International Tax and Public Finance, 10: 107-126.

[14] Devereux, M.P., B. Lockwood and M. Redoano (2006); "Horizontal and Vertical Indirect Tax Competition: Theory and Some Evidence from The USA." Journal of Public Economics doi:10.1016/j.jpubeco.2006.07.005. 
[15] EUbusiness (2004); "Irish PM rejects calls for EU corporate tax harmonization." Available online at http://www.EUbusiness.com, published on 14 May 2004.

[16] Gordon, R. and J.D. Wilson (1986); "An Examination of Mulitjurisdictional Corporate Income Taxation under Formula Apportionment," Econometrica, 54(6): 1357-1373.

[17] Gresik, T. (2001); "The Taxing Task of Taxing Transnationals." Journal of Economic Literature 39: 800-838. Reprinted in Petroleum Regulation within Stable States, by Solveig Glomsrod and Petter Osmundsen eds,. Ashgate Press, 2005.

[18] Groenert, V., M. Wooders and B. Zissimos (2006) "Competition in Standards and Taxes." Vanderbilt University typescript.

[19] Hindriks, J. (1999); "Tax vs. Transfer Competition." Journal of Public Economics, 74: 215234.

[20] Hoyt, W.H. (1995); "Leviathan and Local Tax Policies: Do Local Governments Maximize Revenue?" Working Paper E-185-95, Center for Business and Economic Research, University of Kentucky.

[21] Hoyt, W.H. (1999); "Leviathan, Local Government Expenditures and Capitalization." Regional Science and Urban Economics, 29: 155-171.

[22] Hoyt, W.H. and R.A. Jensen (2001); "Product Differentiation and Public Education." Journal of Public Economic Theory, 3(1): 69-93.

[23] Justman, M., J-F. Thisse and T. Van Ypersele (2002); "Taking the Bite out of Fiscal Competition." Journal of Urban Economics, 52: 294-315.

[24] Justman, M., J-F. Thisse and T. Van Ypersele (2005); "Fiscal Competition and Regional Differentiation," Regional Science and Urban Economics, 35(6): 848-861.

[25] Kanbur, R. and M. Keen (1993); "Jeux Sans Frontieres: Tax Competition and Tax Coordination When Countries Differ in Size." American Economic Review, 83(4): 877-892.

[26] Keen, M. and C. Kotsogiannis (2003); "Leviathan and Capital Tax Competition in Federations," Journal of Public Economic Theory, 5(2): 177-199.

[27] Keen, M. And M. Marchand (1997); "Fiscal Competition and the Pattern of Public Spending." Journal of Public Economics, 66: 33-53.

[28] Kind, H.J., K. Knarvik and G. Schelderup (2000); "Competing for Capital in a 'Lumpy' World" Journal of Public Economics, 78: 253-274.

[29] Kreps, D. and J.A. Scheinkman (1983); "Quantity Precommitment and Bertrand Competition Yield Cournot Outcomes," The Bell Journal of Economics, 14(2): 326-337. 
[30] Lockwood, B. (2001); "Tax Competition and Tax Coordination Under Destination and Origin Principles: A Synthesis." Journal of Public Economics, 81: 279-319.

[31] Lockwood, B. and M. Makris (2006); "Tax Incidence, Majority Voting and Capital Market Integration." Journal of Public Economics, 90: 1007-1025.

[32] Ludema, R.D. and I. Wooton (2000); "Economic Geography and the Fiscal Effects of Regional Integration," Journal of International Economics, 52: 331-357.

[33] Mintz, J. and M. Smart (2004): "Income Shifting, Investment and Tax Competition: Theory and Evidence from Provincial Taxation in Canada." Journal of Public Economics, 88: 11491168.

[34] Mintz, J. and H. Tulkens (1996); "Optimality Properties of Alternative Systems of Taxation of Foreign Capital Income." Journal of Public Economics, 60: 373-399.

[35] Oates, W.E. and R.M. Schwab (1988); "Economic Competition Among countries: Efficiency Enhancing or Distortion Inducing?" Journal of Public Economics, 35: 333-354.

[36] Shaked, A. and J. Sutton (1982); "Relaxing Price Competition Through Product Differentiation," The Review of Economic Studies, 49(1): 3-13.

[37] Sutton, J. (1991); Sunk Costs and Market Structure, MIT Press, Cambridge.

[38] Tiebout, C.M. (1956); "A Pure Theory of Local Expenditures." Journal of Political Economy, 64: 416-24.

[39] Tirole, J. (1998); The Theory of Industrial Organization, MIT Press, Cambridge.

[40] Wilson, J.D. (1986); "A Theory of Interregional Tax Competition." Journal of Urban Economics, 19: 296-315.

[41] Wilson, J.D. (1987); "Trade, Capital Mobility, and Tax Competition." Journal of Political Economy, 95: 835-56.

[42] Wilson, J. (1991); "Tax Competition with Interregional Differences in Factor Endowments." Regional Science and Urban Economics, 21: 423-51.

[43] Wilson, J.D. (1999); "Theories of Tax Competition.” National Tax Journal, 52(2): 269-305.

[44] Wilson, J.D. and E. Janeba (2005); "Decentralization and International Tax Competition." Journal of Public Economics, 89: 1211-1229.

[45] Wilson, J.D. and D.E. Wildasin (2004) "Tax Competition: Bane or Boon?" Journal of Public Economics 88: 1065-1091.

[46] Zissimos, B. and M. Wooders (2006); "Relaxing Tax Competition through Public Good Differentiation." Vanderbilt University Department of Economics Working Paper No. 06-W01R. 
Figure 1

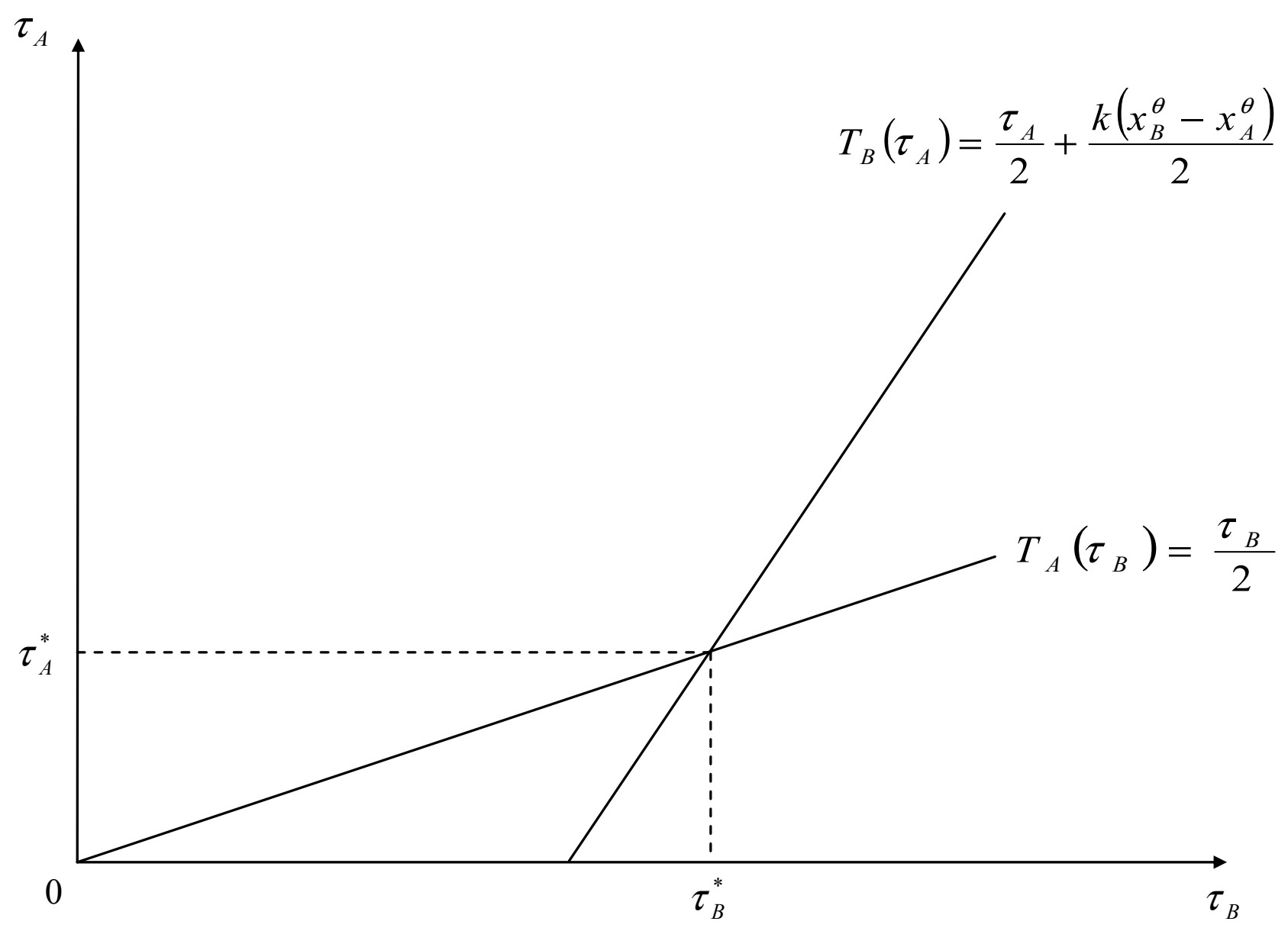

